University of New Hampshire

University of New Hampshire Scholars' Repository

$11-16-2003$

\title{
Aerosol chemical composition in Asian continental outflow during the TRACE-P campaign: Comparison with PEM-West B
}

Jack E. Dibb

University of New Hampshire, jack.dibb@unh.edu

R. Talbot

University of New Hampshire, robert.talbot@unh.edu

Eric Scheuer

University of New Hampshire - Main Campus, Eric.Scheuer@unh.edu

Garry Seid

University of New Hampshire - Main Campus

Melody A. Avery

NASA

See next page for additional authors

Follow this and additional works at: https://scholars.unh.edu/earthsci_facpub

Part of the Atmospheric Sciences Commons

\section{Recommended Citation}

Dibb, J. E., R. W. Talbot, E. M. Scheuer, G. Seid, M. A. Avery, and H. B. Singh (2003), Aerosol chemical composition in Asian continental outflow during the TRACE-P campaign: Comparison with PEM-West B, J. Geophys. Res., 108, 8815, doi:10.1029/2002JD003111, D21.

This Article is brought to you for free and open access by the Earth Sciences at University of New Hampshire Scholars' Repository. It has been accepted for inclusion in Earth Sciences Scholarship by an authorized administrator of University of New Hampshire Scholars' Repository. For more information, please contact Scholarly.Communication@unh.edu. 


\section{Authors}

Jack E. Dibb, R. Talbot, Eric Scheuer, Garry Seid, Melody A. Avery, and H B. Singh 


\title{
Aerosol chemical composition in Asian continental outflow during the TRACE-P campaign: Comparison with PEM-West B
}

\author{
Jack E. Dibb, Robert W. Talbot, Eric M. Scheuer, and Garry Seid \\ Climate Change Research Center, Institute for the Study of Earth, Oceans, and Space, University of New Hampshire, \\ Durham, New Hampshire, USA
}

Melody A. Avery

NASA Langley Research Center, Hampton, Virginia, USA

Hanwant B. Singh

NASA Ames Research Center, Moffett Field, California, USA

Received 31 October 2002; revised 19 February 2003; accepted 24 March 2003; published 11 November 2003.

[1] Aerosol associated soluble ions and the radionuclide tracers ${ }^{7} \mathrm{Be}$ and ${ }^{210} \mathrm{~Pb}$ were quantified in 414 filter samples collected in spring 2001 from the DC-8 during the Transport and Chemical Evolution over the Pacific (TRACE-P) campaign. Binning the data into near Asia (flights from Hong Kong and Japan) and remote Pacific (all other flights) revealed large enhancements of $\mathrm{NO}_{3}^{-}, \mathrm{SO}_{4}^{=}, \mathrm{C}_{2} \mathrm{O}_{4}^{=}, \mathrm{NH}_{4}^{+}, \mathrm{K}^{+}, \mathrm{Mg}^{2+}$, and $\mathrm{Ca}^{2+}$ near Asia. The boundary layer and lower troposphere were most strongly influenced by continental outflow, and the largest enhancements were seen in $\mathrm{Ca}^{2+}$ (a dust tracer) and $\mathrm{NO}_{3}^{-}$(reflecting uptake of $\mathrm{HNO}_{3}$ onto the dust). Comparing the TRACE P near Asia bin with earlier results from the same region during PEM-West B (in 1994) shows at least twofold enhancements during TRACE P in most of the ions listed above. Calcium and $\mathrm{NO}_{3}^{-}$were most enhanced in this comparison as well (more than sevenfold higher in the boundary layer and threefold higher in the lower troposphere). Independent estimation of Asian emissions of gaseous precursors of the aerosol-associated ions suggest only small changes between the two missions, and precipitation fields do not suggest any significant difference in the efficiency of the primary sink, precipitation scavenging. It thus appears that with the possible exception of dust, the enhancements of aerosol-associated species during TRACE P cannot be explained by stronger sources or weaker sinks. We argue that the enhancements largely reflect the fact that TRACE P focused on characterizing Asian outflow, and thus the DC-8 was more frequently flown into regions that were influenced by well-organized flow off the continent. INDEX TERMS: 0305 Atmospheric Composition and Structure: Aerosols and particles $(0345,4801)$; 0365 Atmospheric Composition and Structure: Troposphere-composition and chemistry; 0368 Atmospheric Composition and Structure: Troposphere - constituent transport and chemistry; KEYWORDS: Asian outflow, TRACE-P, aerosol-associated soluble ions, beryllium-7, lead-210

Citation: Dibb, J. E., R. W. Talbot, E. M. Scheuer, G. Seid, M. A. Avery, and H. B. Singh, Aerosol chemical composition in Asian continental outflow during the TRACE-P campaign: Comparison with PEM-West B, J. Geophys. Res., 108(D21), 8815, doi:10.1029/2002JD003111, 2003.

\section{Introduction}

[2] The Transport and Chemical Evolution over the Pacific (TRACE-P) aircraft mission was the third time NASA's Global Tropospheric Experiment has targeted the western north Pacific. TRACE-P deployed two aircraft to conduct intensive sampling flights out of Hong Kong and Yakota Air Force Base in February-April 2001. These operation bases were also used during the Pacific Exploratory Mission (PEM) West A (in 1991) and B (in 1994)

Copyright 2003 by the American Geophysical Union. 0148-0227/03/2002JD003111 campaigns. TRACE-P flights used the combined capabilities of the Dryden DC- 8 and the Wallops P3 to characterize the composition of Asian outflow and assess changes in that composition during transport [Jacob et al., 2003]. The PEM-West campaigns used just the DC-8 in more of a survey mode, addressing several competing objectives.

[3] As the population of Asia grows and industrialization in the region proceeds at an increasing pace, it is expected that export of pollution to the Pacific Ocean and regions even further downwind will increase [Houghton et al., 2001]. Concern over intercontinental transport of materials introduced into the atmosphere by anthropogenic activities has led IGPB's International Global Atmospheric Chemistry 
project to coordinate a new initiative focused on quantifying such long-range impacts. Transport of particles, including relatively coarse dust aerosol mixed with pollution, across the Pacific to western north America has been documented frequently in the past few years [e.g., Gregory et al., 1997; Xiao et al., 1997; Jaffe et al., 1999, 2003; Newell and Evans, 2000; Wilkening et al., 2000; Husar et al., 2001; McKendry et al., 2001; Tratt et al., 2001; Uno et al., 2001; Vaughan et al., 2001; Thulasiraman et al., 2002].

[4] The UNH group made in situ measurements of soluble acidic gases [Talbot et al., 2003] and of aerosolassociated species collected onto filters from the DC-8 as part of TRACE-P. This paper focuses on the filter sampling, which provide distributions of ten water-soluble ionic species and the natural radionuclides ${ }^{7} \mathrm{Be}$ and ${ }^{210} \mathrm{~Pb}$, in the troposphere above the western north Pacific. The suite of ions includes several that are dominantly derived from anthropogenic emissions in much of the Northern Hemisphere (e.g., $\mathrm{NO}_{3}^{-}, \mathrm{SO}_{4}^{-}$, and $\mathrm{NH}_{4}^{+}$), others that have been used to trace biomass burning emissions (e.g., $\mathrm{K}^{+}, \mathrm{PO}_{4}^{=}$, and $\mathrm{C}_{2} \mathrm{O}_{4}^{=}$), and a suite dominated by emissions of soil dust and sea salt into the atmosphere (e.g., $\mathrm{Ca}^{2+}, \mathrm{Mg}^{2+}, \mathrm{Na}^{+}$, and $\mathrm{Cl}^{-}$). We note that airborne dust can have both natural and anthropogenic sources, while generation of sea-salt aerosols is still largely a natural process. Beryllium-7 is a cosmogenic isotope produced in the atmosphere. Maximum production is near $15 \mathrm{~km}$ altitude; thus ${ }^{7} \mathrm{Be}$ is a tracer of stratospheric and upper tropospheric air masses mixing downward into the troposphere. Lead-210 is a daughter of ${ }^{222} \mathrm{Rn}$, which is released from soils and rocks on continents. Therefore ${ }^{210} \mathrm{~Pb}$ can be useful as a tracer of air masses that have been impacted by the continental boundary relatively recently.

[5] Most of the aerosol-associated ions that we measured on filters were also quantified with Particle into Liquid Sampler techniques employed on both the Wallops P3 and the NCAR C-130 (as part of the ACE-Asia campaign) [Ma et al., 2003, Y. Ma et al., Intercomparisons of airborne measurements of fine particle ionic chemical composition during TRACE-P and ACE-Asia, submitted to Journal of Geophysical Research, 2003, hereinafter referred to as Ma et al., submitted manuscript, 2003]. Several additional techniques to characterize the chemical composition of aerosols were also used on the C-130. As part of TRACE-P, three instrument intercomparison flight legs were conducted where the DC- 8 and P3 endeavored to fly in close formation for up to 1.5 hours [Eisele et al., 2003]. In addition, the P3 conducted similar coordinated sampling for intercomparison with the C-130 during part of two flights. K. Moore et al. (Intercomparison of aerosol physical, optical and chemical characteristics measured from 3 platforms during TRACE-P and ACE-Asia, submitted to Journal of Geophysical Research, 2003) and Ma et al. (submitted manuscript, 2003) discuss the results of these intercomparisons for the range of aerosol measurements that were made on the different platforms. A primary conclusion was that inlet and operational details made it difficult to compare the composition measurements, since most, if not all, of the instruments were measuring different size fractions. Because of this complication, we restrict our attention to the DC- 8 filter sampling. However, the bulk aerosol sampling system we used on the DC- 8 has not changed since 1991, and our analysis has been by ion chromatography throughout the GTE program. Thus our TRACE $P$ results should be comparable to all previous missions where we measured bulk aerosol composition from the DC-8. In particular, we will compare TRACE-P results to those from PEM-West $\mathrm{B}$, which was conducted in the same general region during the same season in 1994.

\section{Methods}

\subsection{Sampling}

[6] We collected aerosols from the DC-8 using the UNH dual sampling probe that we have employed for all GTE missions on the DC-8 (all missions since 1991 except for TRACE A). This system was reproduced and also flown on the P3 during PEM Tropics B and is described in detail by Dibb et al. [2002] and references therein. These probes employ curved leading edge nozzles, isoaxially mounted inside cylindrical shrouds, and have adjustable sampling flow rates to maintain isokinetic sampling (within 10\%). Dibb et al. [2002] discuss evidence we have obtained over several past missions which indicates that the way we operate these probes allows us to sample ambient aerosol particles with diameters up to at least 6 microns without significant losses in the sampling probe.

[7] As in past missions, sampling during TRACE-P was generally restricted to level flight legs. One of the sampling probes was used to collect aerosol-associated soluble ion samples onto $90 \mathrm{~mm}$ diameter 2 micron Millipore Fluoropore filters. The other probe was used to collect aerosolassociated ${ }^{7} \mathrm{Be}$ and ${ }^{210} \mathrm{~Pb}$ on $90 \mathrm{~mm}$ diameter Whatman $\mathrm{GF} /$ A glass fiber filters. Continual improvement in the sensitivity of our analytical system, low and stable blank values from the Fluoropore filters, and relatively heavy aerosol loading over the western Pacific allowed us to reduce filter exposure time compared with all previous missions. A total of 414 filter pairs were exposed on the 17 science (transit and intensive) flights the DC-8 conducted during TRACE-P. Sampling intervals ranged from 1 to $40 \mathrm{~min}$ but averaged just over 6 min at altitudes below $1 \mathrm{~km}, 9$ minutes from 1 to $6 \mathrm{~km}, 14 \mathrm{~min}$ between 6 and $9 \mathrm{~km}$, and $17 \mathrm{~min}$ at altitudes above $9 \mathrm{~km}$. Median sample exposure times in these altitude bins were slightly shorter than the means but not by more than $10 \%$.

\subsection{Analysis}

[8] Exposed filters were stored in zero-air-purged clean room bags in a cooler [see Dibb et al., 2002] until they were extracted immediately after each flight. Because our acidic gas sampling system [Talbot et al., 2003] includes two custom ion chromatographs configured for anion analyses, it has been our practice to quantify anions in the aerosol filter extracts on the next nonflight day (usually the next day) and to preserve the remaining solution with chloroform. Cations are quantified in our laboratories in New Hampshire as soon as the samples have been returned at the end of the campaign. We began TRACE-P in this fashion, but the large number of aerosol samples collected made it impossible to keep up with the anion analyses. All extracts from flights 4 through 10 were analyzed in the field, for flights 11-20 the preserved extracts were returned to New Hampshire for quantification of both anions and cations. We 
Table 1. Summary of the 37 Blank Filters Generated During TRACE-P

\begin{tabular}{|c|c|c|c|c|c|c|c|c|c|c|c|}
\hline $\begin{array}{l}\text { Bin, } \\
\mathrm{km}\end{array}$ & $\begin{array}{c}\text { Mean } \\
\text { Volume, } \\
\text { SCM }\end{array}$ & $\mathrm{Cl}^{-}$ & $\mathrm{NO}_{3}^{-}$ & $\mathrm{PO}_{4}^{=}$ & $\mathrm{SO}_{4}^{=}$ & $\mathrm{C}_{2} \mathrm{O}_{4}^{=}$ & $\mathrm{Na}^{+}$ & $\mathrm{NH}_{4}^{+}$ & $\mathrm{K}^{+}$ & $\mathrm{Mg}^{2+}$ & $\mathrm{Ca}^{2+}$ \\
\hline \multicolumn{12}{|c|}{ Loading on Blanks, nmol filter $^{-1}$} \\
\hline Mean & & 7.2 & 1.5 & 0.1 & 1.8 & 0.4 & 14.6 & 3.5 & 1.9 & 0.7 & 7.3 \\
\hline Std. & & 2.6 & 0.3 & 0.2 & 0.3 & 0.5 & 2.1 & 0.7 & 1.0 & 0.4 & 3.6 \\
\hline \multicolumn{12}{|l|}{ Dev. } \\
\hline \multicolumn{12}{|c|}{ Uncertainty in Mixing Ratios Due to Blanks, ppt } \\
\hline$<1$ & 2.18 & 26.5 & 2.8 & 2.3 & 2.6 & 5.1 & 21.1 & 6.7 & 10.0 & 4.4 & 37.2 \\
\hline $1-6$ & 2.88 & 20.0 & 2.1 & 1.8 & 1.9 & 3.9 & 15.9 & 5.1 & 7.6 & 3.3 & 28.2 \\
\hline $6-9$ & 3.10 & 18.6 & 2.0 & 1.6 & 1.8 & 3.6 & 14.8 & 4.7 & 7.0 & 3.1 & 26.2 \\
\hline$>9$ & 2.58 & 22.4 & 2.4 & 2.0 & 2.2 & 4.3 & 17.8 & 5.6 & 8.5 & 3.7 & 31.5 \\
\hline
\end{tabular}

also reanalyzed anions in the samples from the first seven flights and found no significant changes due to storage (for up to 6 weeks).

[9] Blank Fluoropore filters were generated (2-3 per flight) by placing a filter into a cassette, inserting it into the sampling probe, and opening all valves to allow airflow for less than $5 \mathrm{~s}$. These blanks were then stored in purged clean room bags and extracted along with the exposed filters. We have found that variability in the loading of analyte ions on blank filters often constitutes the largest source of uncertainty in determining the mixing ratios of aerosol-associated ions. Dibb et al. [2002] noted that Fluoropore blanks during PEM Tropics B were much lower and less variable than we had ever obtained with Zefluor filters, reducing uncertainty and leading to lower detection limits. Mean values of the ion loadings on TRACE-P blank filters (Table 1) were similar (often slightly higher) than those for PEM Tropics B, but the variability was less by $50-100 \%$. The more stable blanks yield lower uncertainty, but this is partly negated by the smaller sample volumes during TRACE-P. Table 1 shows the contribution variability in the blanks makes to uncertainty in calculated mixing ratios for samples with volumes equal to the mean in each of 4 altitude bins. (Note that we report mixing ratios of aerosol-associated ions in units of parts per trillion ( $p p t=$ (picomoles of analyte) (mole of air) ${ }^{-1}$ ) to facilitate comparison to gaseous precursors.) Samples with larger (smaller) volumes of air filtered will have proportionately smaller (larger) uncertainty. During TRACE-P the range of sample volumes was $0.9-4.0,1.4-6.8,1.2-7.0$, and 1.25.8 standard cubic meters (SCM) in the boundary layer, $1-$ $6 \mathrm{~km}, 6-9 \mathrm{~km}$, and $>9 \mathrm{~km}$ altitude bins, respectively. Therefore the uncertainty in mixing ratios reported for any sample rarely differ from those listed in Table 1 by more than a factor of two.

[10] Glass fiber filters were returned to UNH by express mail in several groups during the deployment, so that ${ }^{7} \mathrm{Be}$ (half-life $=53$ days) could be quantified by nondestructive gamma spectroscopy as quickly as possible. We quantify ${ }^{210} \mathrm{~Pb}$ through alpha spectroscopic determination of ${ }^{210} \mathrm{Po}$, after allowing at least 11 months for the daughter to "grow in" [Dibb et al., 1996].

\subsection{Binning and Averaging}

[11] One focus of the following discussion is comparing the distribution of aerosol-associated species between TRACE P and PEM West B. Dibb et al. [1996, 1997] found it convenient to divide the study region sampled during PEM West A and B into two broad subregions: near Asia and remote north Pacific. We will follow this lead and consider that all of the TRACE-P flights out of Hong Kong and Yakota (except the transit from Japan to Kona) sampled the near-Asia region (Figure 1). We consider the westbound transit flights (Dryden to Kona, Kona to Guam, and the first half of Guam to Hong Kong) and the return (Japan to Kona to Dryden, including the local flight out of Kona), to have sampled the remote Pacific. This division is based on the operational bases of the DC-8, which guided the scientific objectives of each flight [Jacob et al., 2003], rather than any strict geographic consideration. However, the vast majority of near Asia samples were collected west of $150 \mathrm{E}$, with nearly all remote samples east of this longitude (Figure 1).

[12] The near-Asia region substantially overlaps the comparable region considered during both PEM West campaigns, with some potentially significant differences that will be discussed more fully later. The TRACE-P remote Pacific data set has a much greater emphasis on the eastern Pacific and correspondingly less sampling in the tropical and subtropical western north Pacific, than either PEM West campaign. TRACE-P sampling was also restricted to latitudes south of $47 \mathrm{~N}$, contrasting the transit flights through Anchorage on both PEM West campaigns. It should also be emphasized that the number of samples in both regions was much higher during TRACE-P (284 versus 72 near Asia samples, 130 versus 44 remote samples in PEM West B, with even fewer samples in PEM West A).

[13] We have used the altitude bins defined by Dibb et al. [1997]; <1 km to represent the boundary layer, $1-6 \mathrm{~km}$ as a lower troposphere bin, and 6-9 and $>9 \mathrm{~km}$ to represent the middle and upper troposphere, respectively. A disproportionate fraction of our filter samples (approximately 40\% in each of the geographic regions) fall into the boundary layer bins, largely due to the shorter sample times we used at low altitude. To further highlight the larger size of the TRACE-P data set, we note that more samples were collected in the near Asia boundary layer during TRACE-P than the total at all altitudes in both regions during PEM West B.

[14] We also compare the distributions of selected gaseous species $\left(\mathrm{O}_{3}, \mathrm{HNO}_{3}\right.$, and PAN) to the aerosol-associated species which are the primary focus. All of these gases were

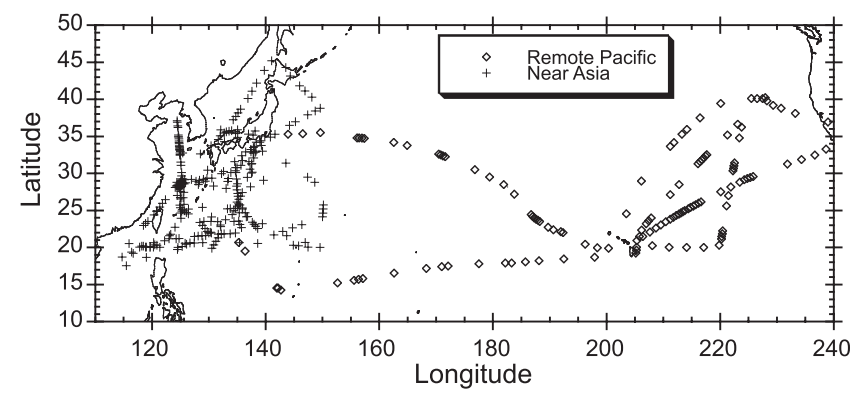

Figure 1. Geographic distribution of bulk aerosol filter samples collected from the DC- 8 during TRACE-P. Samples shown with crosses are considered to be near Asia; those indicated by diamonds are considered to be over the remote Pacific in this paper. 

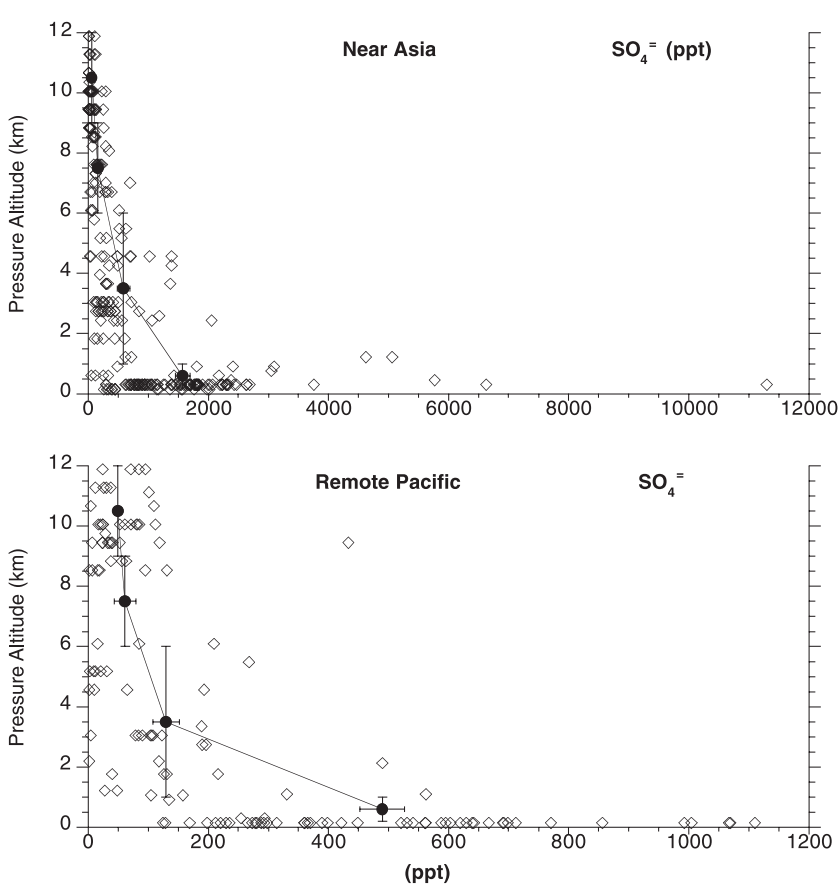

Figure 2. Mixing ratios of aerosol-associated $\mathrm{SO}_{4}^{\overline{-}}$ as a function of altitude in the two geographic bins. The solid diamonds (connected by the lines) show the means in four altitude bins $(<1,1-6,6-9$, and $>9 \mathrm{~km})$. Vertical error bars on the solid diamonds indicate the depth of the altitude bins, while the horizontal bars show the standard error of the bin means.

measured at higher frequency than we collected aerosol filters, and detailed discussions of their high-resolution data sets are presented in companion papers in this issue. In this paper we exclusively use a merged data set, generated by the GTE project office, wherein all fast response measurements were averaged to the varying integration time of the individual aerosol filter samples.

\section{Results}

[15] The distribution of $\mathrm{SO}_{4} \overline{-}$ as a function of altitude in the two geographic bins illustrates our sampling density, and highlights two features that are common to the distributions of many of the aerosol-associated species (Figure 2). In the boundary layer mixing ratios vary over more than an order of magnitude, but even the lowest values tend to be enhanced compared with those in the free troposphere. As a result, the boundary layer means exceed those in the lower troposphere by more than a factor of 2.5 and are at least $15-$ fold higher than upper troposphere means. Similarly rapid decreases with altitude characterize the distributions of $\mathrm{Cl}^{-}$, $\mathrm{NO}_{3}^{-}, \mathrm{Na}^{+}, \mathrm{NH}_{4}^{+}, \mathrm{K}^{+}, \mathrm{Mg}^{2+}$, and $\mathrm{Ca}^{2+}$, with the trend more striking near Asia for $\mathrm{Ca}^{2+}$ and $\mathrm{K}^{+}$(Table 2). It should be noted that the summary statistics tabulated in Table 2 consider only those samples for which the individual ion was above detection limit and thus may considerably overestimate the mean and median in some of the higher altitude bins (e.g., $\mathrm{PO}_{4}^{=}$and $\mathrm{Cl}^{-}$above $9 \mathrm{~km}$ near Asia, $\mathrm{PO}_{4}^{=}, \mathrm{Cl}^{-}, \mathrm{Na}^{+}, \mathrm{Mg}^{2+}, \mathrm{Ca}^{2+}$ in the highest remote bin). (Dibb et al. [1997] also omitted below detection limit samples when calculating summary statistics for the PEM West B data set.) However, it must also be pointed out that despite the smaller sample volumes for TRACE P samples, a smaller proportion of samples were reported as below detection limit than in all previous GTE campaigns. Below $6 \mathrm{~km}$, all aerosol-associated species except ${ }^{7} \mathrm{Be}$ and $\mathrm{PO}_{4}^{=}$ were quantified in more than $90 \%$ of the near Asia samples and in more than $65 \%$ of the remote Pacific samples. At higher altitudes all species (except for $\mathrm{PO}_{4}^{=}$far from Asia) were quantified in more than $27 \%$ of all samples, while those species usually dominating the accumulation mode $\left(\mathrm{NH}_{4}^{+}\right.$and $\left.\mathrm{SO}_{4}^{=}\right)$were too low to quantify in just two and

Table 2. Concentrations of Aerosol-Associated Species in Eight Geographic/Altitude Bins Over the North Pacific During TRACE-P ${ }^{\mathrm{a}}$

\begin{tabular}{|c|c|c|c|c|c|c|c|c|c|c|c|c|}
\hline & $\mathrm{Cl}^{-}$ & & & 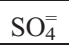 & $\mathrm{C}_{2}$ & $\mathrm{Na}^{+}$ & & & & $a_{2}^{2+}$ & ${ }^{7} \mathrm{Be}$ & ${ }^{210} \mathrm{~Pb}$ \\
\hline \multicolumn{13}{|c|}{$\begin{array}{l}\text { Near Asia } \\
\text { km (118 Samples) }\end{array}$} \\
\hline$n$ & & & 46 & & 114 & & & 115 & & & 78 & 18 \\
\hline & 2022 & 839 & 33 & 157 & 67 & 2238 & 1613 & 276 & 366 & 1366 & 368 & 20.3 \\
\hline & 150 & 136 & 3 & 121 & 5 & 163 & 147 & 29 & 30 & 243 & 37 & 1.2 \\
\hline Med. & 1839 & 508 & 32 & 1497 & 56 & 1878 & 1332 & 210 & 281 & 407 & 289 & 16.9 \\
\hline
\end{tabular}

\begin{tabular}{|c|c|c|c|c|c|c|c|c|c|c|c|c|}
\hline \multirow[b]{2}{*}{$n^{\mathrm{b}}$} & \multicolumn{12}{|c|}{$1-6 \mathrm{~km}$ (67 Samples) } \\
\hline & 47 & 66 & 57 & 67 & 67 & 61 & $67^{7}$ & 67 & 63 & 58 & 47 & 67 \\
\hline Mean & 214 & 220 & 8 & 587 & 39 & 422 & 528 & 98 & 156 & 969 & 500 & 10. \\
\hline Serr $^{\mathrm{c}}$ & 64 & 72 & 2 & 103 & 5 & 152 & 82 & 25 & 53 & 345 & 68 & 0.6 \\
\hline Med. & 45 & 73 & 5 & 346 & 28 & 61 & 371 & 42 & 25 & 135 & 442 & \\
\hline \multicolumn{13}{|c|}{$6-9 \mathrm{~km}$ (44 Samples) } \\
\hline$n^{\mathrm{b}}$ & 15 & 39 & 19 & 44 & 44 & 24 & 44 & 33 & 25 & 24 & 31 & 44 \\
\hline Mean & 66 & 42 & 4 & 158 & 12 & 73 & 148 & 17 & 23 & 118 & 847 & 7.5 \\
\hline Serr $^{\mathrm{c}}$ & 21 & 10 & 0.6 & 21 & 1.5 & 29 & 20 & 3 & 7 & 35 & 213 & 0.6 \\
\hline Med. & 21 & 25 & 3 & 115 & 12 & 8 & 115 & 10 & 8 & 52 & 562 & 6.5 \\
\hline \multicolumn{13}{|c|}{$>9$ km (55 Samples) } \\
\hline$n^{\mathrm{b}}$ & 12 & 35 & 11 & 52 & 46 & 18 & 53 & 24 & 16 & 22 & 45 & 55 \\
\hline Mean & 100 & 12 & 4 & 54 & 7 & 72 & 58 & 15 & 28 & 81 & 1057 & 9 \\
\hline Ser & 30 & 3 & 0.5 & & 0.9 & 23 & 10 & 6 & 11 & 25 & 240 & \\
\hline
\end{tabular}

$\begin{array}{llllllllllll}\text { Med. } 34 & 5 & 4 & 27 & 6 & 27 & 37 & 4 & 11 & 28 & 504 & 4.8\end{array}$

\begin{tabular}{|c|c|c|c|c|c|c|c|c|c|c|c|c|}
\hline \multicolumn{13}{|c|}{$\begin{array}{c}\text { Remote Pacific } \\
<1 \text { km (51 Samples) }\end{array}$} \\
\hline$n^{\mathrm{b}}$ & 51 & 51 & 3 & 51 & 49 & 51 & 49 & 51 & 51 & 42 & 19 & 51 \\
\hline Mean & 2608 & 139 & 12 & 490 & 26 & 2523 & 522 & 79 & 261 & 93 & 381 & 7.0 \\
\hline Serr ${ }^{c}$ & 242 & 11 & 4 & 37 & 2 & 211 & 37 & 6 & 23 & 10 & 51 & 0.4 \\
\hline led. & 1659 & 129 & 16 & 422 & 23 & 1637 & 466 & 65 & 167 & 85 & 450 & 6.8 \\
\hline \multicolumn{13}{|c|}{ 1-6 km (34 Samples) } \\
\hline$n^{\mathrm{b}}$ & 24 & 27 & 5 & 34 & 33 & 22 & 32 & 28 & 20 & 13 & 12 & 34 \\
\hline Iean & 491 & 29 & 5 & 130 & 11 & 506 & 137 & 23 & & & 25 & 9 \\
\hline $\mathrm{err}^{\mathrm{c}}$ & 168 & 6 & 3 & 22 & 1 & 163 & 24 & 5 & 1 & 33 & 1 & .9 \\
\hline Med. & 55 & 18 & 5 & 105 & 9 & 114 & 129 & 15 & 22 & 25 & 367 & 7.0 \\
\hline \multicolumn{13}{|c|}{ 6-9 km (12 Samples) } \\
\hline$n^{\mathrm{b}}$ & 2 & 10 & 3 & 12 & 11 & 4 & 12 & 8 & & 3 & & 12 \\
\hline Gean & 11 & 9 & 1 & 6 & 21 & 15 & 86 & 15 & & 11 & 57 & .9 \\
\hline Serr ${ }^{c}$ & 6 & 2 & 2 & 18 & 5 & 8 & 221 & 6 & 0.7 & 6 & 312 & 1.0 \\
\hline Med. & 11 & 9 & 1 & 47 & 18 & 15 & 82 & 5 & 0.5 & 15 & 400 & 6.4 \\
\hline \multicolumn{13}{|c|}{$>9 \mathrm{~km}$ (33 Samples) } \\
\hline$n^{\mathrm{b}}$ & 12 & 21 & 3 & 33 & 29 & 12 & 33 & 14 & 13 & 11 & 24 & 33 \\
\hline Mean & 99 & 7 & 3 & 49 & 18 & 125 & 60 & 17 & & 33 & 1838 & 6.5 \\
\hline Serr ${ }^{c}$ & 32 & 1 & 2 & 6 & 2 & 43 & 9 & 9 & 1 & 7 & 578 & 0.6 \\
\hline Med. & 49 & 5 & 2 & 37 & 18 & 62 & 52 & 5 & 0.8 & 22 & 691 & 6.1 \\
\hline
\end{tabular}

${ }^{\text {a }}$ Ions are reported in mixing ratios as parts per trillion (ppt) while the two radionuclide tracers are given in $\mathrm{fCi} \mathrm{scm}^{-1}$.

${ }^{\mathrm{b}}$ Here $n$ is the number of samples above detection limit.

${ }^{\mathrm{c}}$ Serr is the standard error (=standard deviation/square root of $n$ ). 
three samples, respectively (Table 2). Oxalate and ${ }^{210} \mathrm{~Pb}$ also decrease with altitude, but their gradients are less steep than the ions listed above. The distribution of ${ }^{7} \mathrm{Be}$ is unique among all the aerosol-associated species, increasing strongly with altitude (Table 2). This is not unexpected, given the production profile (maximum near $15 \mathrm{~km}$ ) and the much higher concentrations of ${ }^{7} \mathrm{Be}$ in the stratosphere.

[16] The distribution of $\mathrm{SO}_{4}^{=}$also illustrates the enhancement of several aerosol-associated species near Asia. Peak mixing ratios in the boundary layer and lower troposphere were roughly an order of magnitude higher in this region (Figure 2), and the average was more than 2.6-fold higher in all near Asia bins below $9 \mathrm{~km}$ (Table 2). Nitrate and $\mathrm{Ca}^{2+}$ showed even larger enhancements $(>4.7-$ and $>10.7$-fold, respectively) near Asia than did $\mathrm{SO}_{4}^{=}$. Oxalate, $\mathrm{NH}_{4}^{+}, \mathrm{K}^{+}$, and ${ }^{210} \mathrm{~Pb}$ enhancements near Asia were comparable to those in $\mathrm{SO}_{4}^{=}$but only in the boundary layer and lower troposphere, while the $\mathrm{Mg}^{2+}$ enhancement near Asia increased with altitude. In contrast, mean mixing ratios of $\mathrm{Cl}^{-}$ and $\mathrm{Na}^{+}$were higher in the remote low-altitude bins, and ${ }^{7} \mathrm{Be}$ mean concentrations did not differ by more than $30 \%$ below $9 \mathrm{~km}$.

[17] Calcium shows the largest enhancements near Asia of all aerosol-associated species (Table 2). Soluble $\mathrm{Ca}^{2+}$ is often considered to be the best tracer of continental dust among the ionic species, though sea salt is also a significant source of $\mathrm{Ca}^{2+}$ which can dominate in the marine boundary layer far from land [e.g., Dibb et al., 1999a]. During TRACE-P it is clear that outflow of Asian dust was the overwhelmingly dominant source of $\mathrm{Ca}^{2+}$, as it was greatly in excess of the sea-salt ratio in all near Asia free troposphere samples, most of the remote tropospheric samples, and in many boundary layer samples from both regions. The abundance of Asian dust in the near Asia region also impacted the distribution of $\mathrm{Mg}^{2+}$, particularly below $9 \mathrm{~km}$. However, the larger contribution that sea salt makes to $\mathrm{Mg}^{2+}$ mixing ratios $\left(\mathrm{Mg}^{2+}\right.$ is more than fivefold more abundant than $\mathrm{Ca}^{2+}$ in sea salt, on a molar basis) masked the enhancement of dust-derived $\mathrm{Mg}^{2+}$ in the near Asia region. The dust fraction of $\mathrm{Mg}^{2+}$ was likely $10-15$ times higher near Asia than over the remote Pacific, but the lower seasalt mixing ratios near Asia resulted in total $\mathrm{Mg}^{2+}$ enhancements that were roughly a factor of 2 below $6 \mathrm{~km}$, (Table 2 ). In the remote Pacific the relationships between $\mathrm{Na}^{+}$and $\mathrm{Mg}^{2+}$ are consistent with sea salt being the dominant source of $\mathrm{Mg}^{2+}$. It should be noted that the abundance of dust near Asia is so high in some samples that a significant fraction of the measured $\mathrm{Na}^{+}$may also be derived from this source [e.g., Song and Carmichael, 2001]. In a later section, we will use $\mathrm{Na}^{+}$to estimate the non-sea-salt (nss) fraction of several ions but recognize that these will be underestimates to the extent that Asian dust is a source of the measured $\mathrm{Na}^{+}$. Jordan et al. [2003a] base much of their discussion on similarly estimated nss fractions and argue that dust-derived $\mathrm{Na}^{+}$is only likely to be significant in a small number of samples originating from a limited region.

[18] As noted above, $\mathrm{NO}_{3}^{-}$shows the second highest enhancements near Asia, followed by $\mathrm{SO}_{4}^{=}$and $\mathrm{NH}_{4}^{+}$ (Table 2). The precursors of all three of these ions are emitted by a range of anthropogenic activities; hence they are often considered to be pollution tracers. Jordan et al. [2003a] demonstrate that uptake of $\mathrm{HNO}_{3}$ onto Asian dust
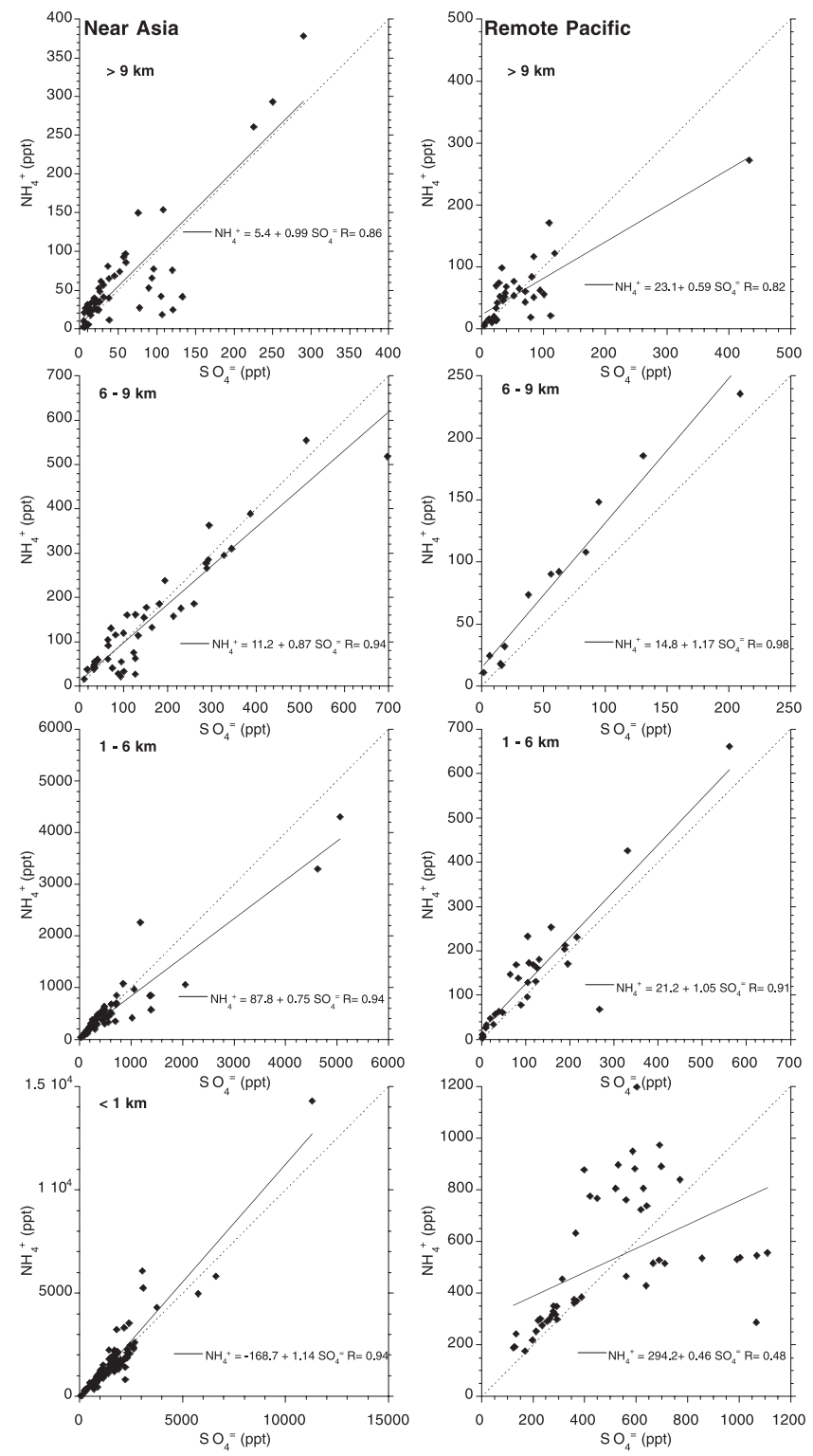

Figure 3. Scatter plots of $\mathrm{NH}_{4}^{+}$against $\mathrm{SO}_{4}^{=}$in the same eight bins. The dotted lines have slopes of unity, corresponding to $\mathrm{NH}_{4} \mathrm{HSO}_{4}$. Solid lines are least squares fits of the data.

can account for many of the highest mixing ratios of aerosol-associated $\mathrm{NO}_{3}^{-}$, while uptake of $\mathrm{HNO}_{3}$ onto seasalt aerosol contributes to elevated $\mathrm{NO}_{3}^{-}$in boundary layer regions with smaller dust loading [Talbot et al., 2003]. Sulfur dioxide and $\mathrm{H}_{2} \mathrm{SO}_{4}$ can react with sea salt, dust, and $\mathrm{NH}_{3}$ to form aerosol $\mathrm{SO}_{4}^{=}$. It is likely that all three processes contributed to the aerosol-associated $\mathrm{SO}_{4}^{=}$we measured during TRACE-P, though the strong relationships between $\mathrm{SO}_{4}^{=}$and $\mathrm{NH}_{4}^{+}$suggest that formation of $\mathrm{NH}_{4} \mathrm{HSO}_{4}$ may have been extensive near Asia (Figure 3). If most of the $\mathrm{SO}_{4}^{=}$exported from Asia is associated with $\mathrm{NH}_{4}^{+}$in accumulation mode particles rather than on coarse sea salt and dust, the potential for very long-range transport across the Pacific will be increased. Scatter plots of $\mathrm{SO}_{4}^{=}$versus $\mathrm{Ca}^{2+}$ (not shown) show essentially no relationship except that 
samples with very strong dust signals $\left(4-15 \mathrm{ppb} \mathrm{Ca}^{2+}\right)$ also have elevated $\mathrm{SO}_{4}^{=}(2-5 \mathrm{ppb})$. Similarly, $\mathrm{SO}_{4}^{=}$shows no clear relationship to $\mathrm{Na}^{+}$(plots not shown). Unfortunately, size-resolved measurements, which could confirm that $\mathrm{SO}_{4}^{=}$ is dominantly associated with fine particles, were not made on the DC-8. However, measurements made from the NCAR C-130 during ACE Asia did find that $\mathrm{SO}_{4}^{=}$was predominantly in the accumulation mode (B. Huebert, personal communication, November 2001). On the other hand, $\mathrm{SO}_{4}^{=}$does show general correlation with $\mathrm{PO}_{4}^{=}$and $\mathrm{C}_{2} \mathrm{O}_{4}^{=}$, particularly near Asia (not shown). Their relationships to $\mathrm{SO}_{4}^{=}$, and their enhancements in the two lowaltitude near-Asia bins (Table 2), suggest that $\mathrm{PO}_{4}^{=}$and $\mathrm{C}_{2} \mathrm{O}_{4}^{=}$are also anthropogenically impacted components of the Asian outflow sampled during TRACE-P.

\section{Discussion}

[19] Jordan et al. [2003b], Russo et al. [2003], and Talbot et al. [2003] all use the same binning scheme based on air mass origin (from trajectories) to characterize the composition of Asian outflow sampled from the DC-8 during TRACE-P. Blake et al. [2003], combined the extensive data sets on hydrocarbons and halocarbons collected from the DC-8 and P3 and searched for signatures of specific types of emissions (e.g., regional differences in urban/industrial sources, biogenic emissions, biomass burning, etc.). All of these authors conclude that the continental outflow generally contained a mixture of emissions that made it difficult to pinpoint the influence of specific sources or regions. Bartlett et al. [2003] focused on $\mathrm{CH}_{4}$ measurements from both aircraft and used spatial binning to address similar issues. They also found that the distribution of $\mathrm{CH}_{4}$ and its relations to selected NMHC reflected the influence of a complex mixture of sources but show that biomass burning and biofuel combustion emissions from Southeast Asia had a dominant influence on upper tropospheric air in the central Pacific. Simulations with the global three-dimensional model, GEOS-CHEM, indicate that biomass burning emissions in south east Asia had to be lifted to the middle and upper troposphere before they could be advected into the TRACE P study region [Liu et al., 2003]. Carmichael et al. [2003] find that their regional-scale three-dimensional chemical transport model (STEM 2K1) reproduced this feature as well, and $M a$ et al. [2003] present fine $\mathrm{K}^{+}$ measurements on the P3 which show biomass burning plumes from Southeast Asia above polluted boundary layer outflow. Simulations with STEM 2K1 also suggested that near Asia the processes exporting dust and pollution into the Pacific generally caused layering, with dust overlying urban/industrial pollution (G. Carmichael, personal communication, June 2002). M. Chin et al. (An assessment of regional Pacific Rim sulfur chemistry based on observations from TRACE-P and ACE-Asia, submitted to Journal of Geophysical Research, 2003) found similar vertical separation of dust and pollution in their global model, consistent with observations from previous airborne sampling [Clarke and Kapustin, 2002].

[20] We examined the vertical distributions of aerosolassociated ions in the near-Asia bin to see if they provide evidence that outflowing pollution (from urban/industrial sources and from combustion of biomass) and dust are
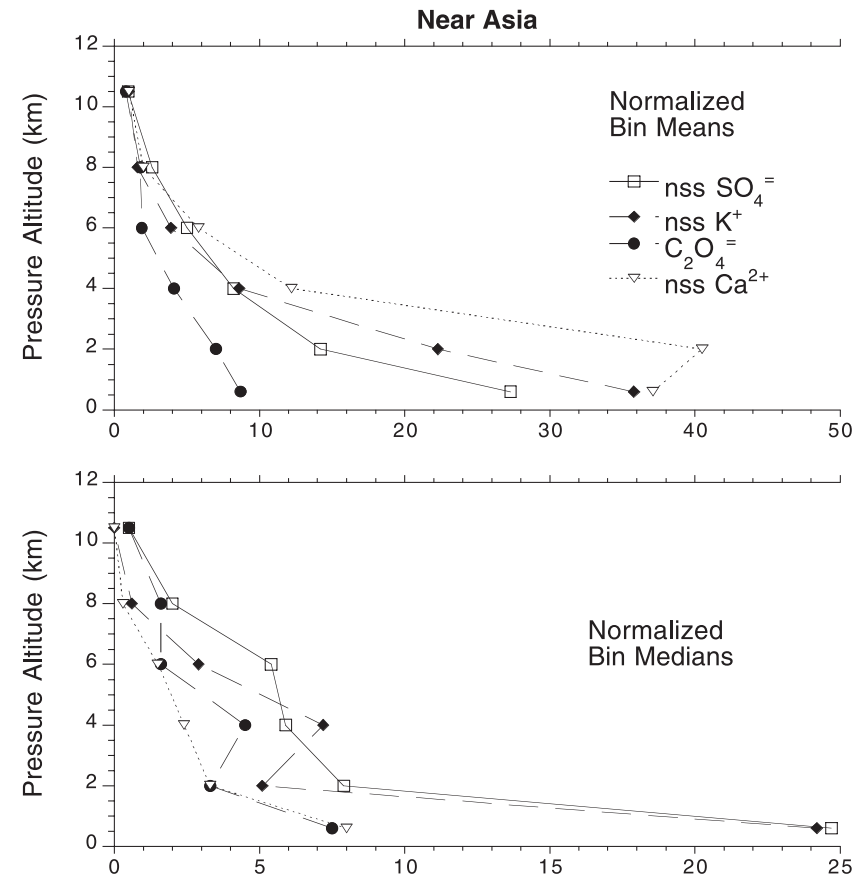

Figure 4. Altitude distributions of $\mathrm{nss}^{-} \mathrm{SO}_{4}^{=}$(considered to represent urban/industrial emissions), nss $\mathrm{K}^{+}$, and $\mathrm{C}_{2} \mathrm{O}_{4}^{=}$ (often tracers of biomass burning) and nss $\mathrm{Ca}^{2+}$ in the TRACE-P near-Asia region. Sea-salt corrections use $\mathrm{Na}^{+}$as the tracer. The points are plotted at the mean (upper panel) and median (lower panel) values of normalized mixing ratios in $<1,1-3,3-5,5-7,7-9$, and $>9 \mathrm{~km}$ altitude bins. The normalization process consisted simply of dividing mixing ratios in each sample by the mean in the $>9 \mathrm{~km}$ bin.

transported at different altitudes. Non-sea-salt $\mathrm{Ca}^{2+}$ was selected as the dust tracer, using $\mathrm{Na}^{+}$to estimate the seasalt fraction. Non-sea-salt $\mathrm{SO}_{4}^{=}$represents urban/industrial pollution, while nss $\mathrm{K}^{+}$and $\mathrm{C}_{2} \mathrm{O}_{4}^{=}$where included as the best tracers of biomass or biofuel combustion among the aerosol-associated ions $\left(\mathrm{C}_{2} \mathrm{O}_{4}^{=}\right.$and its precursor $\mathrm{H}_{2} \mathrm{C}_{2} \mathrm{O}_{4}$ is a product of combustion generally but has been shown to be greatly enhanced in boreal wild fires [Lefer et al., 1994; Gorzelska et al., 1994]). Simply dividing the 1-9 km altitude band into four bins of $2 \mathrm{~km}$ thickness reveals that nss $\mathrm{SO}_{4}^{=}$(and also $\mathrm{NH}_{4}^{+}$) is greatly elevated below $1 \mathrm{~km}$, while the highest mean nss $\mathrm{Ca}^{2+}$ (also nss $\mathrm{Mg}^{2+}$ ) mixing ratios are found in the $1-3 \mathrm{~km}$ range. In order to show all four tracers on a comparable scale, we divided the mixing ratios of tracer ions in each sample by their means above $9 \mathrm{~km}$ and then calculated summary statistics for the normalized values in six altitude bins $(<1,1-3,3-5,5-7,7-9$, and $>9 \mathrm{~km}$ ) (Figure 4). Enhanced transport of dust between 1 and $3 \mathrm{~km}$ occurs in well-organized plumes with very elevated concentrations [Jordan et al., 2003a, 2003b], as demonstrated by the fact that the mean for this bin but not the median is the highest in the near-Asia region. It should be noted that there is substantial dust in the boundary layer bin, mixing with the pollution and also that nss $\mathrm{SO}_{4}^{=}$ is present in abundance in the $1-3 \mathrm{~km}$ bin where dust is highest (Figure 4). One result of mixing dust with the 


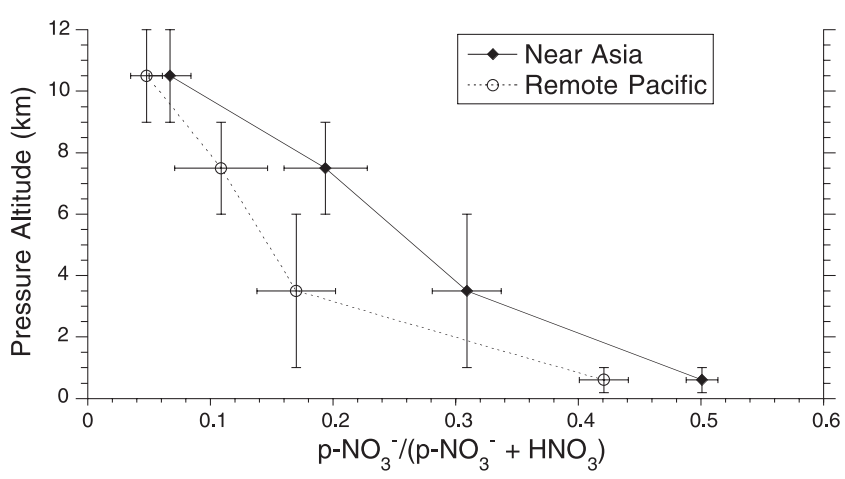

Figure 5. Mean partitioning of inorganic nitrate between the gas and particulate phases in the eight bins defined in Table 2. Error bars as defined for Figure 2.

pollutant emissions during transport over the Pacific is that $\mathrm{HNO}_{3}$ is taken up by the dust [Jordan et al., 2003a], causing a larger fraction of inorganic $\mathrm{NO}_{3}^{-}$to be found in the particulate phase in the near-Asia region in all altitude bins up to $9 \mathrm{~km}$ (Figure 5). The mean mixing ratios of nss $\mathrm{K}^{+}$and $\mathrm{C}_{2} \mathrm{O}_{4}^{=}$smoothly decrease with altitude, like nss $\mathrm{SO}_{4}^{=}$ (Figure 4), suggesting that their sources are mixed with urban/industrial emissions before reaching the TRACE-P study region. It does not appear that the large-scale distributions of aerosol-associated ions provide any evidence for an influence from biomass/biofuel combustion that can be separated from the general urban/industrial emissions in the regions sampled by the DC- 8 .

\subsection{Insights From the Radionuclide Tracers}

[21] Relatively strong correlations between ${ }^{210} \mathrm{~Pb}$ and $\mathrm{O}_{3}$, and weak or no relationships between ${ }^{7} \mathrm{Be}$ and $\mathrm{O}_{3}$ during both of the PEM West campaigns suggested that tropospheric production was a much more significant $\mathrm{O}_{3}$ source than injection from the stratosphere for the Pacific region during the campaigns [Dibb et al., 1996, 1997]. In the fall of 1991 (PEM West A), ${ }^{210} \mathrm{~Pb}$ and $\mathrm{O}_{3}$ were correlated throughout the troposphere in both regions; during the spring of 1994 (PEM West B) this relationship was only apparent over the remote Pacific.

[22] The relationship between ${ }^{7} \mathrm{Be}$ and $\mathrm{O}_{3}$ during TRACE-P argues for a minor contribution from the stratosphere in this region during spring 2001 as well (Figure 6). A small number of samples with very high values result in relatively high correlation coefficients $(>0.78)$ in the top two nearAsia bins and above $9 \mathrm{~km}$ over the remote Pacific, but the bulk of the data in these bins show essentially no relationship. At lower altitudes in both regions the relationships are weak, with $\mathrm{O}_{3}$ tending to be anticorrelated with ${ }^{7} \mathrm{Be}$ below $6 \mathrm{~km}$ far from Asia. There was also little correlation between ${ }^{210} \mathrm{~Pb}$ and $\mathrm{O}_{3}$ in the near-Asia region (Figure 7). Above $9 \mathrm{~km}$ there is a reasonably strong relationship $\left(\mathrm{O}_{3}=28.0+5.2\left({ }^{210} \mathrm{~Pb}\right), \mathrm{R}=0.58\right)$ if the four stratospheric samples $\left(\mathrm{O}_{3}>200 \mathrm{ppb}\right)$ are omitted. Over the remote Pacific the relationship between ${ }^{210} \mathrm{~Pb}$ and $\mathrm{O}_{3}$ was strongest in the two bins above $6 \mathrm{~km}$, though the slopes were just over half as large as in the highest near Asia altitude bin (Figure 7). We have previously argued that strong correlations between these species reflect advection (vertical and horizontal) of ${ }^{222} \mathrm{Rn}$ and $\mathrm{O}_{3}$ precursors from the polluted continental boundary layer, with ${ }^{210} \mathrm{~Pb}$ and $\mathrm{O}_{3}$ building up over time during subsequent transport [Dibb et al., 1996, 1997, 1999b].

\subsection{Comparison With PEM West B}

[23] As noted earlier, the TRACE-P remote Pacific data set is based on three flights between Hawaii and the west coast of North America plus the westbound transits through Guam to Hong Kong and the eastbound flight from Japan to Hawaii (Figure 1). In contrast, the remote Pacific data set from PEM West B was based on flights out of Guam which targeted tropical and subtropical air masses near $150 \mathrm{E}$. In both campaigns the remote regions provide a sharp contrast to near Asia air masses, but the TRACE-P data set could be more influenced by aged Asian outflow that had transited the Pacific and recirculated in the "river of pollution" [Renner, 2000; Staudt et al., 2001; Martin et al., 2003]. This region
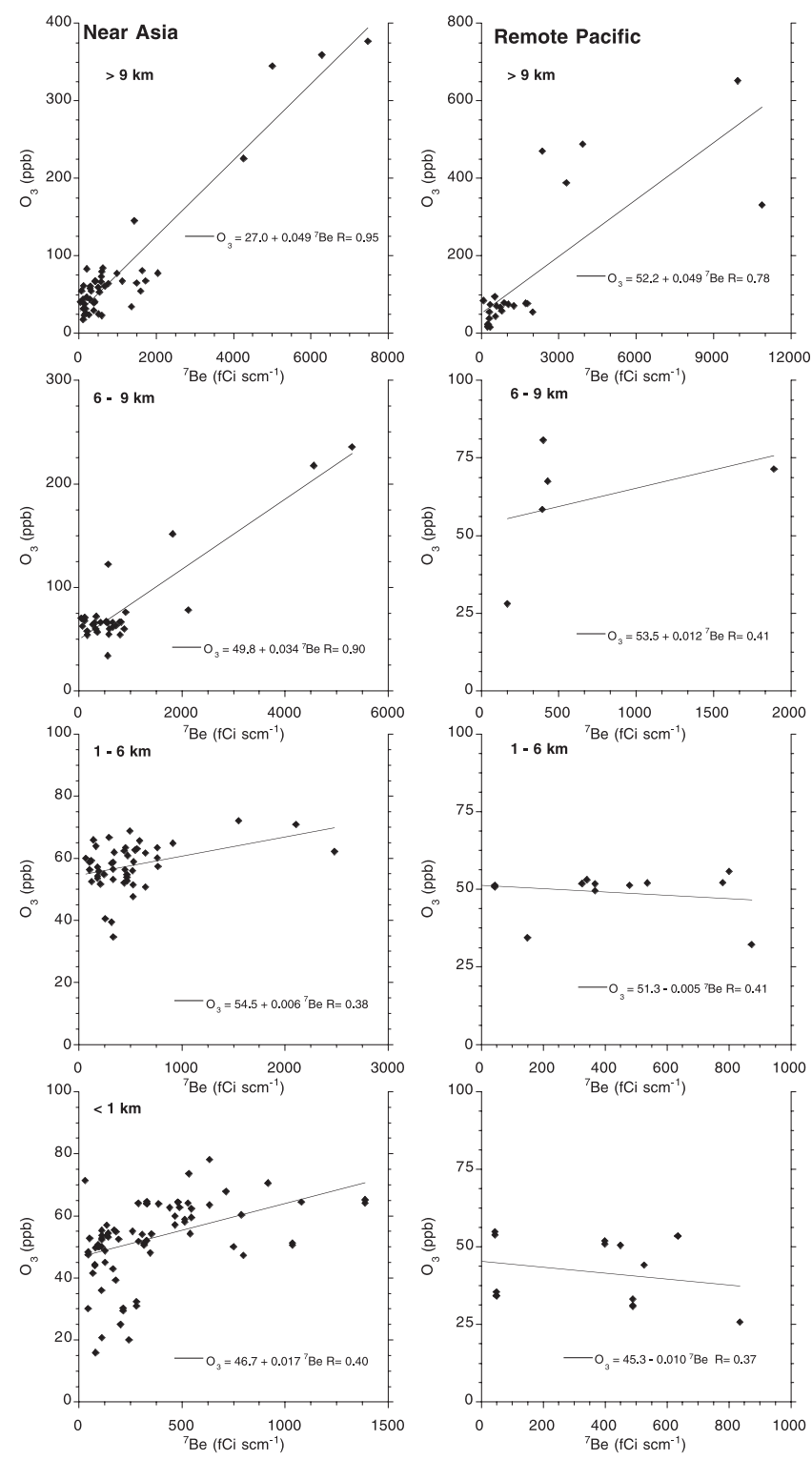

Figure 6. Scatter plots of $\mathrm{O}_{3}$ against ${ }^{7} \mathrm{Be}$ in the eight bins defined in Table 2. Lines are least squares fits of the data. 

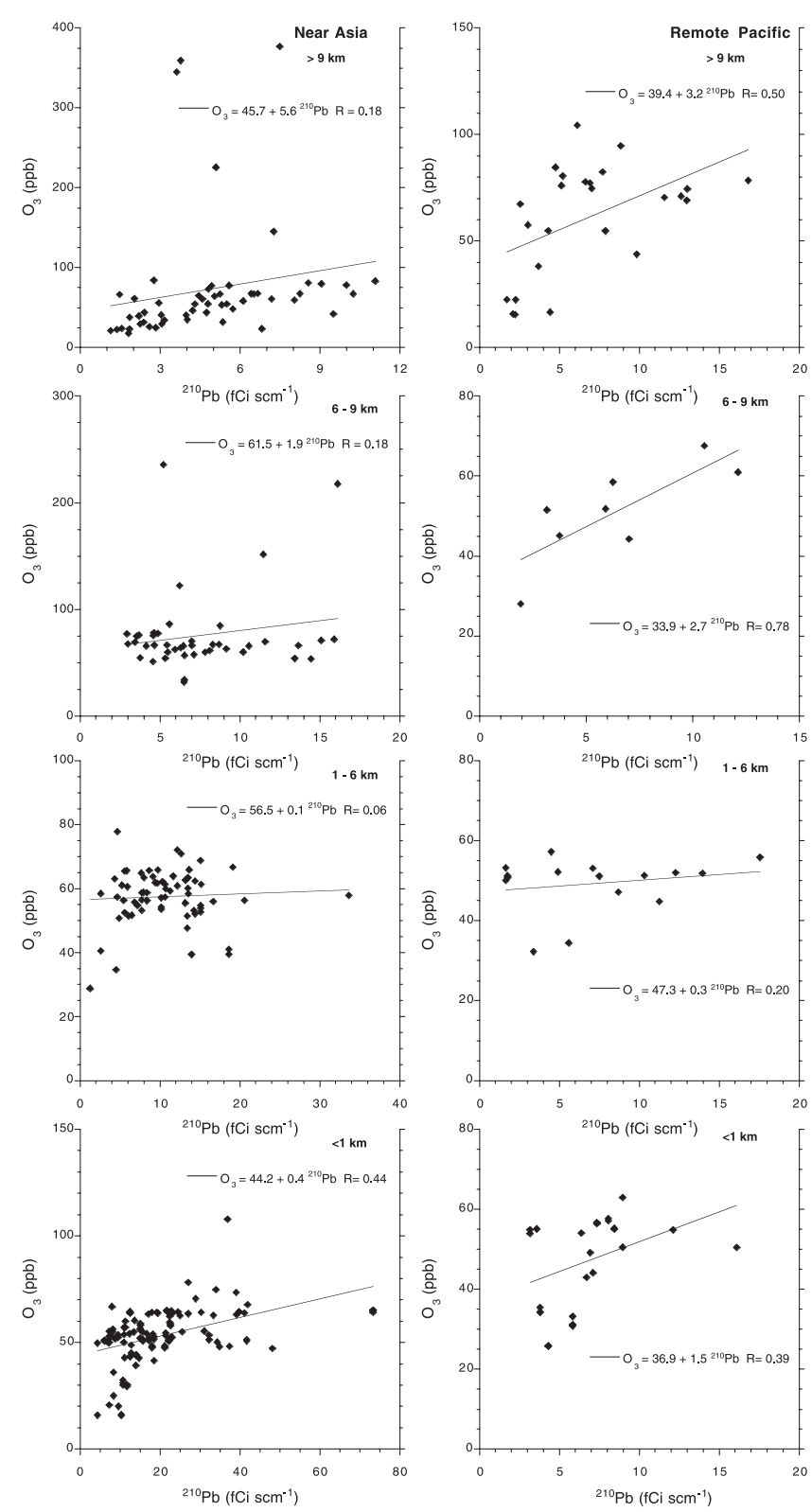

Figure 7. Scatter plots of $\mathrm{O}_{3}$ against ${ }^{210} \mathrm{~Pb}$ in the four near-Asia altitude bins. Lines are least squares fits of the data.

may also be influenced by North American outflow to some extent. The near-Asia region data sets would appear to be more directly comparable, since they are based on similar flights by the DC- 8 from the same operational bases in Hong Kong and Yakota, Japan. However, we must point out that no sampling was conducted in the region bounded approximately by $27-37$ N, $120-135$ E during PEM West B. Several TRACE-P flights specifically targeted this near China region (Figure 1) and encountered very strong outflow.

[24] The aerosol-associated tracers of dust and pollution were all higher in TRACE-P than PEM West B (Figure 8). Calcium near Asia was more than 16 times higher in the boundary layer, nearly 6 times higher in the $1-6 \mathrm{~km}$ bin, and showed more than twofold enhancement at higher altitudes. At low altitudes over the remote Pacific, $\mathrm{Ca}^{2+}$ was likewise roughly twofold higher during TRACE-P. Nitrate showed the second largest enhancements in the near Asia low-altitude bins (factors of 3 and 7 in the lower troposphere and boundary layer) but only increased (a factor of 2) in the boundary layer over the remote Pacific. Enhancements of $\mathrm{SO}_{4}^{=}$and $\mathrm{NH}_{4}^{+}$(TRACE-P $>2.5$ and $>1.7$ times higher, respectively) were larger in the remote region and extended through the full DC-8 altitude range (Figure 8). Near Asia the average $\mathrm{SO}_{4}^{=}$mixing ratios were 2.4-3.4 times higher during TRACE-P from $9 \mathrm{~km}$ to the surface, contrasting small $(10-30 \%) \mathrm{NH}_{4}^{+}$enhancements in all bins except the boundary layer where TRACE-P was 2.5 times higher than PEM West B. It is important to point out that ions with major contributions from sea salt, and the
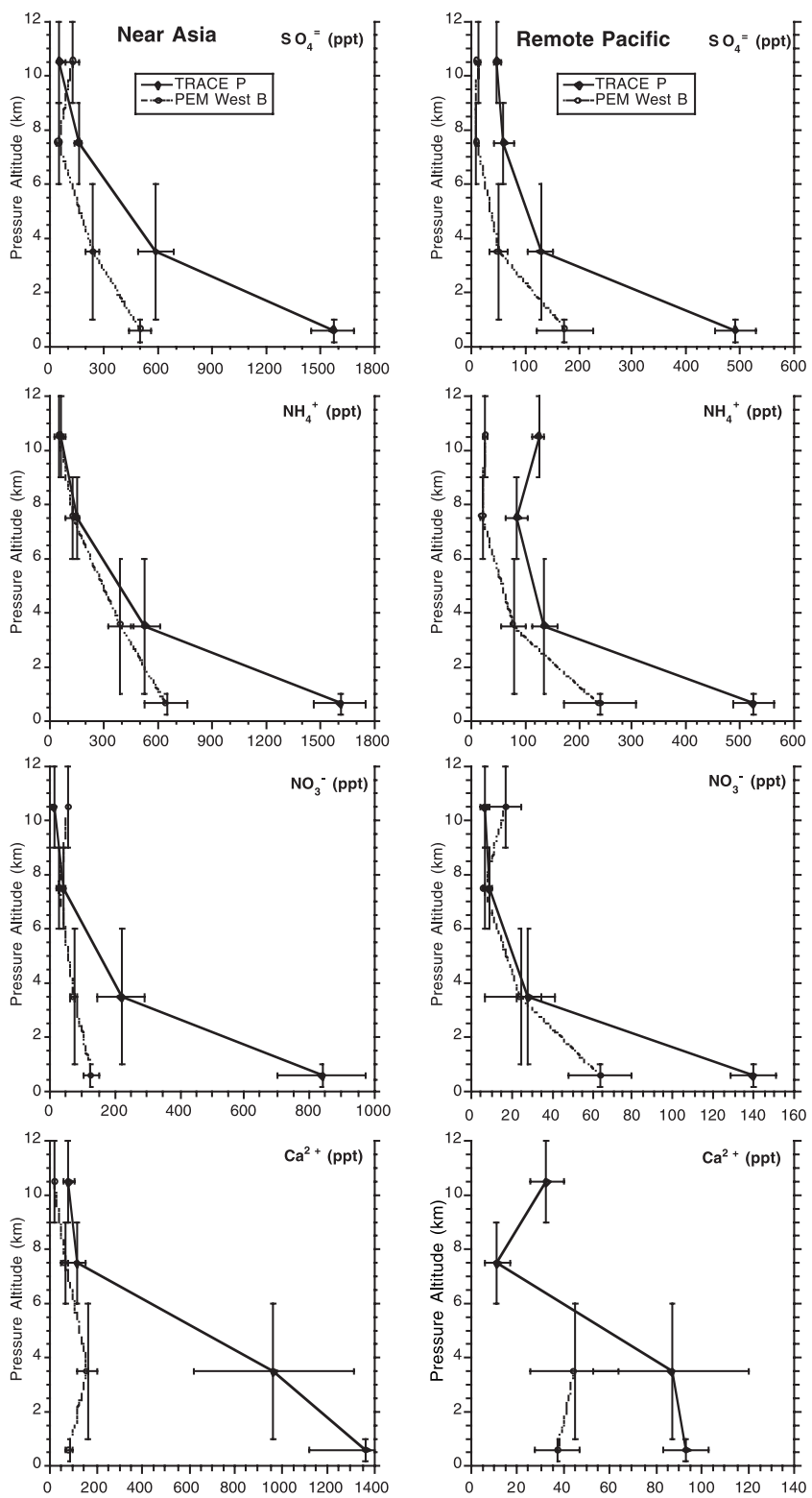

Figure 8. Comparison of mean mixing ratios of $\mathrm{SO}_{4}^{=}$, $\mathrm{NH}_{4}^{+}, \mathrm{NO}_{3}^{-}$, and $\mathrm{Ca}^{2+}$ in four altitude bins in regions near to, and far from, Asia between TRACE-P and PEM West B. Error bars as defined in Figure 2. 

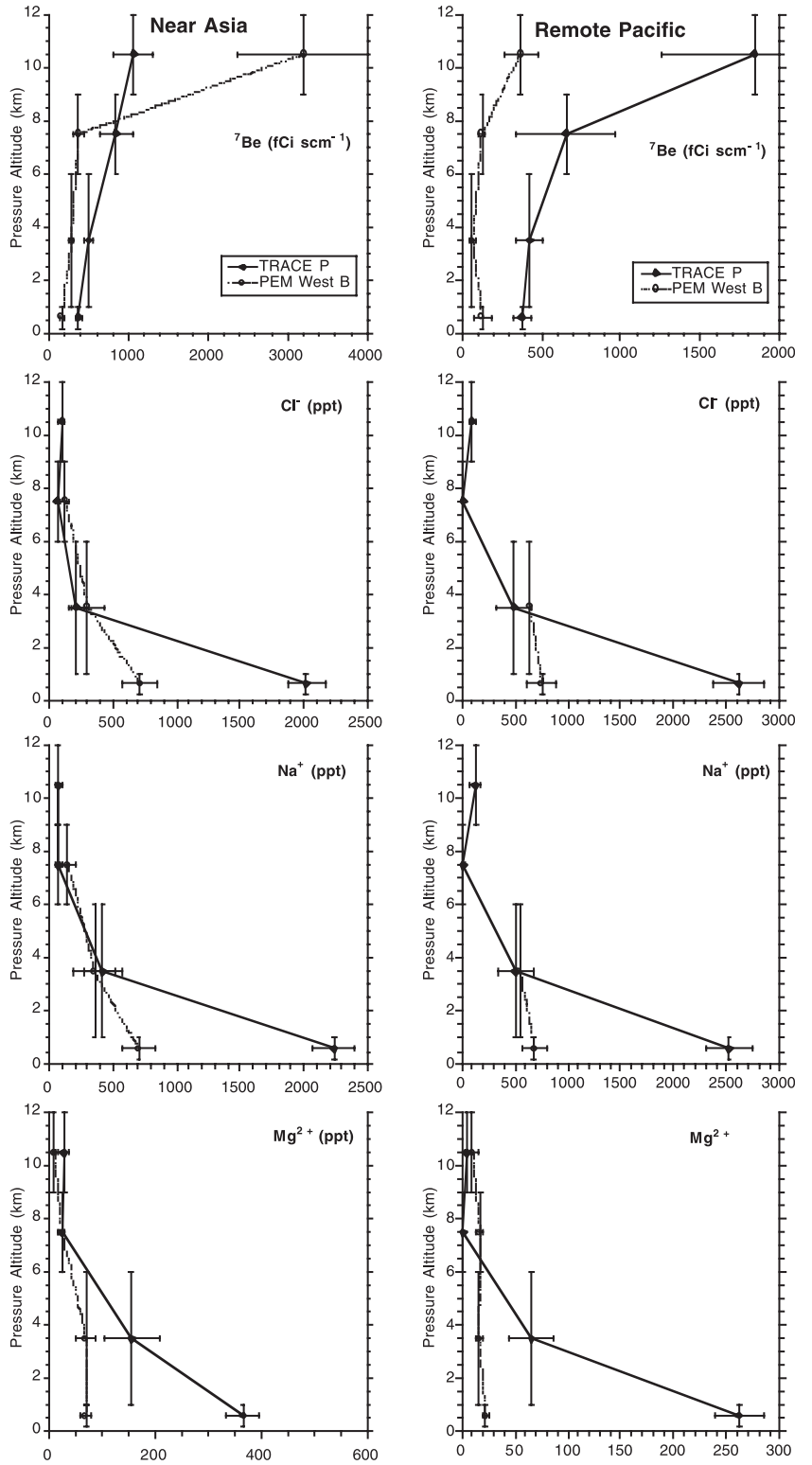

Figure 9. As in Figure 8 but for ${ }^{7} \mathrm{Be}, \mathrm{Cl}^{-}, \mathrm{Na}^{+}$, and $\mathrm{Mg}^{2+}$.

cosmogenic radionuclide ${ }^{7} \mathrm{Be}$, were also higher during TRACE-P in some of the bins (Figure 9). Sodium, $\mathrm{Cl}^{-}$, and $\mathrm{Mg}^{2+}$ were all enhanced by at least a factor of 2.8 in the boundary layer in both regions. It is likely that the enhancements of $\mathrm{Mg}^{2+}$ in both lower troposphere bins, which are not seen in the other sea-salt species (Figure 9), reflect contributions from dust, as suggested by the $\mathrm{Ca}^{2+}$ distributions (Figure 8). Beryllium-7 was higher during TRACE-P in all bins except near Asia above $9 \mathrm{~km}$ (the high concentrations in this bin during PEM West B reflect extended sampling in and near a tropopause fold [Dibb et al., 1997]). Enhancements of ${ }^{7} \mathrm{Be}$ were larger (3.1 to 6.4 times higher during TRACE-P) over the remote Pacific than near Asia $(1.8-2.3$ below $9 \mathrm{~km})$.

[25] Sharply higher concentrations of many aerosol-associated species over the Pacific are to some extent an anomaly in the TRACE-P data set. Most comparisons of the distributions of trace gases between TRACE-P and PEM
West B found small differences or changes that appear to reflect seasonal (e.g., $\mathrm{O}_{3}$ ) or global trends (e.g., $\mathrm{CH}_{4}$ ) [Bartlett et al., 2003; Blake et al., 2003; Russo et al., 2003; Talbot et al., 2003; D. D. Davis et al., A comparison of photochemical environments in the NW Pacific as observed during NASA's PEM-West B [1994] and TRACE-P [2001] airborne field studies, submitted to Journal of Geophysical Research, 2003]. Several different scenarios may have contributed to the changes in distributions of aerosolassociated species depicted in Figures 8 and 9. Our comparison may have generated large apparent differences that are not "real." The issue of whether an airborne campaign captures a regionally representative data set is always an important question. On the large scale, the meteorolgical conditions and sampling regions were very similar between PEM West B and TRACE-P [Fuelberg et al., 2003], though Liu et al. [2003) suggest that more frequent cold surges enhanced boundary layer outflow of Asian air to the Pacific during TRACE-P. We will examine the impact of differences in sampling between the two missions shortly but first consider potential causes for much higher levels of dust and aerosol-associated pollutants in 2001 versus 1994. Clearly, increased emissions in Asia are expected to impact much of the troposphere above the Pacific and further downwind. However, greater export from Asia during TRACE-P than PEM West B should be apparent as increases in many gaseous pollutants as well. Assuming that emissions from Asia have not greatly increased, higher mixing ratios of aerosols exported from Asia could be explained by a weaker sink, i.e., less efficient removal of particles by precipitation scavenging. In the following, we present available evidence on differences in scavenging, Asian emissions, and possible transport/sampling bias between TRACE-P and PEM West B.

\subsubsection{Scavenging}

[26] Concentrations of ${ }^{7} \mathrm{Be}$ above the northern Pacific during both PEM West campaigns were very low compared with expectations and our observations over the south Pacific during PEM Tropics A [Dibb et al., 1996, 1997, 1999a]. We interpreted these low values as evidence of extensive removal by scavenging; hence the higher concentrations observed during TRACE-P (Figure 9) may reflect reduced removal of aerosols over the northern Pacific. We have also found that ${ }^{210} \mathrm{~Pb}$ and its relationship to sparingly soluble gaseous pollutants (specifically precursors to PAN [Dibb et al., 1996, 1997] and NMHC emitted in wild fires [Dibb et al., 1999b]) can provide insight into scavenging during deep wet convection. During the PEM West campaigns we found that ${ }^{210} \mathrm{~Pb}$ tended to be strongly correlated with PAN, but not aerosol $\mathrm{NO}_{3}^{-}, \mathrm{HNO}_{3}$, or their sum (termed $\mathrm{t}-\mathrm{NO}_{3}^{-}$), and argued that $\mathrm{HNO}_{3}$ had been scavenged in the wet convective pumping that lifted ${ }^{222} \mathrm{Rn}$ and pollutants out of the Asian boundary layer. Interestingly, ${ }^{210} \mathrm{~Pb}$ and PAN were correlated in the near Asia and remote regions during PEM West $\mathrm{A}$, but only in the remote region during PEM West $\mathrm{B}$.

[27] Nitric acid and PAN were clearly enhanced in Asian outflow during TRACE-P (mean mixing ratios were 2.63.9 and 5.1-11.5 times higher, respectively, in our near Asia bins below $6 \mathrm{~km}$ ) (see also Talbot et al. [2003]). However, like ${ }^{210} \mathrm{~Pb}$, there were very small differences in 

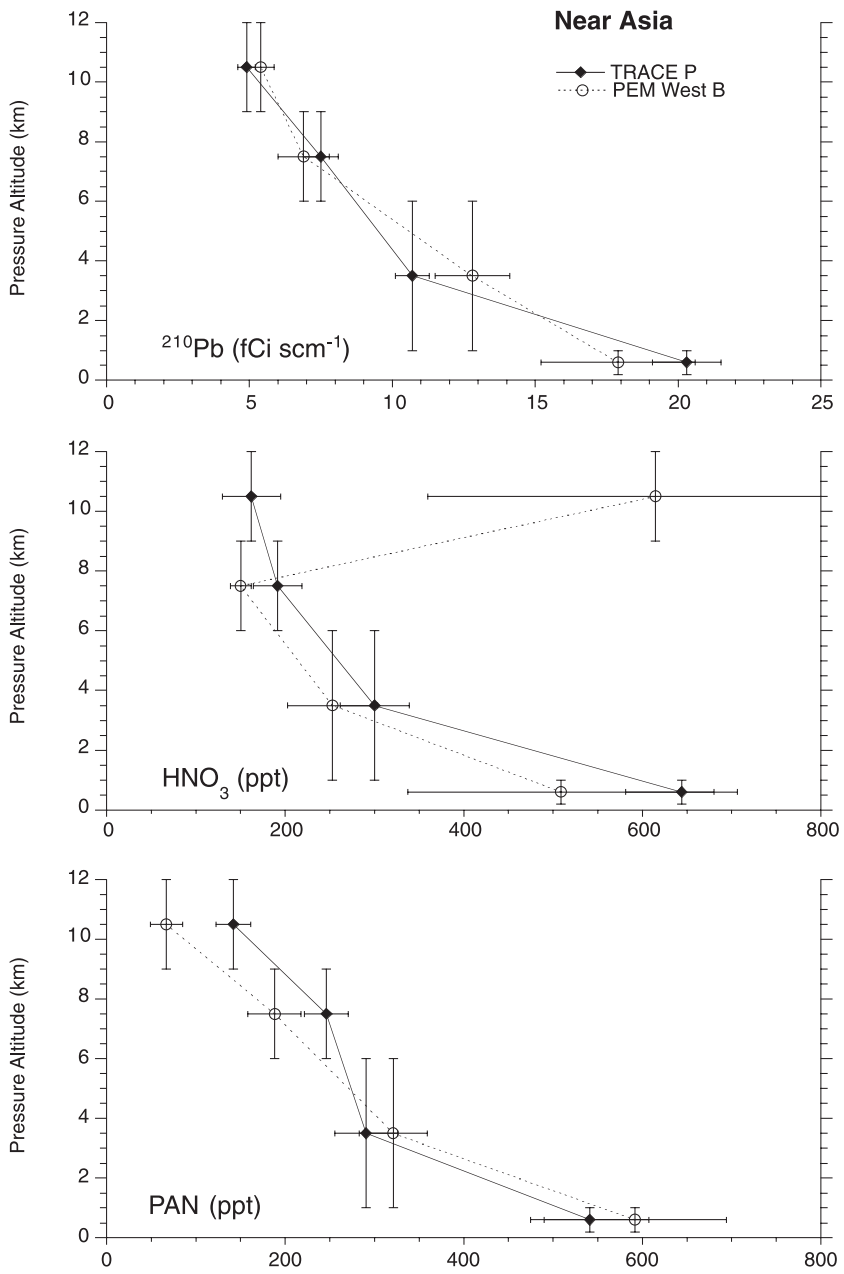

Figure 10. Comparison of mean mixing ratios of ${ }^{210} \mathrm{~Pb}$, $\mathrm{HNO}_{3}$, and PAN in the four near-Asia altitude bins between TRACE-P and PEM West B. Error bars as defined in Figure 2.

their distributions near Asia between PEM West B and TRACE-P (Figure 10). We note that if export of $\mathrm{HNO}_{3}$ did not change much between the two campaigns, the close similarity in $\mathrm{HNO}_{3}$ distributions over the western Pacific would argue that precipitation scavenging was not significantly more efficient during PEM West B. TRACE-P also resembled PEM West $\mathrm{B}$ in the weak relationships between ${ }^{210} \mathrm{~Pb}$ and PAN near Asia (Figure 11). More importantly, the relationships between ${ }^{210} \mathrm{~Pb}$ and $\mathrm{t}-\mathrm{NO}_{3}^{-}$were also quite weak (Figure 12) (the same is true for $\mathrm{HNO}_{3}$ and $\mathrm{NO}_{3}^{-}$ considered separately (not shown)). If removal of $\mathrm{HNO}_{3}$ in precipitation explains the poor correlations during PEM West B, similarly weak relationships during TRACE P argue against significantly reduced scavenging as an explanation for the higher concentrations of aerosol-associated species in the latter campaign.

[28] We also note that Fuelberg et al. [2003] found no differences in the large-scale precipitation fields between TRACE-P and PEM West B. Examination of SSMI rainfall products and GPCP precipitation anomaly fields likewise failed to reveal any persistent differences in precipitation anywhere in eastern Asia or over the western Pacific that would indicate greater efficiency of scavenging during the PEM West study period. Liu et al. [2003] find that deep convective activity was enhanced over south east Asia during TRACE-P compared with PEM West B, but its impact was largely to lift biomass burning emissions into the upper troposphere. In summary, we do not think the higher concentrations of aerosol-associated ions during TRACE P can be attributed to a weaker sink.

\subsubsection{Emissions}

[29] Advection of Asian dust over the Pacific has long been recognized as an important feature of the northern hemisphere. A particularly large event just after the TRACE-P deployment ended attracted much public attention when the plume was tracked all the way across North America [e.g., Thulasiraman et al., 2002]. It also appears that the frequency and severity of Chinese dust storms extending to eastern China and the western Pacific is increasing [Menon et al., 2002]. Unpublished Chinese data indicates that Beijing experienced more dusty days in 2001 than in any year since 1966, with more than twice as many reports in 2001 than in 1994 (R. Arimoto, personal communication, June 2002). As noted above, no striking differ-

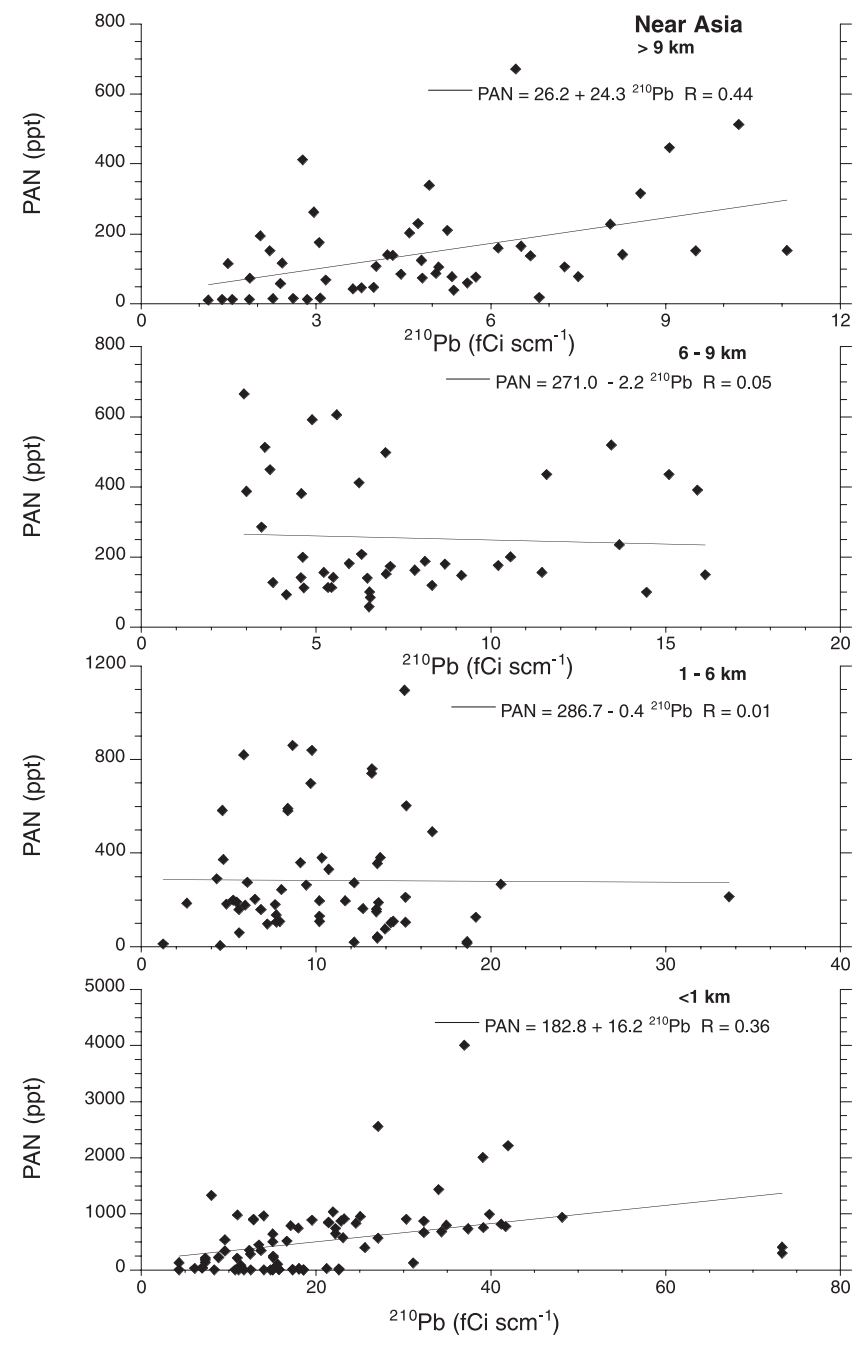

Figure 11. Scatter plots of PAN against ${ }^{210} \mathrm{~Pb}$ in the four near-Asia altitude bins. Lines are least squares fits to the data. 


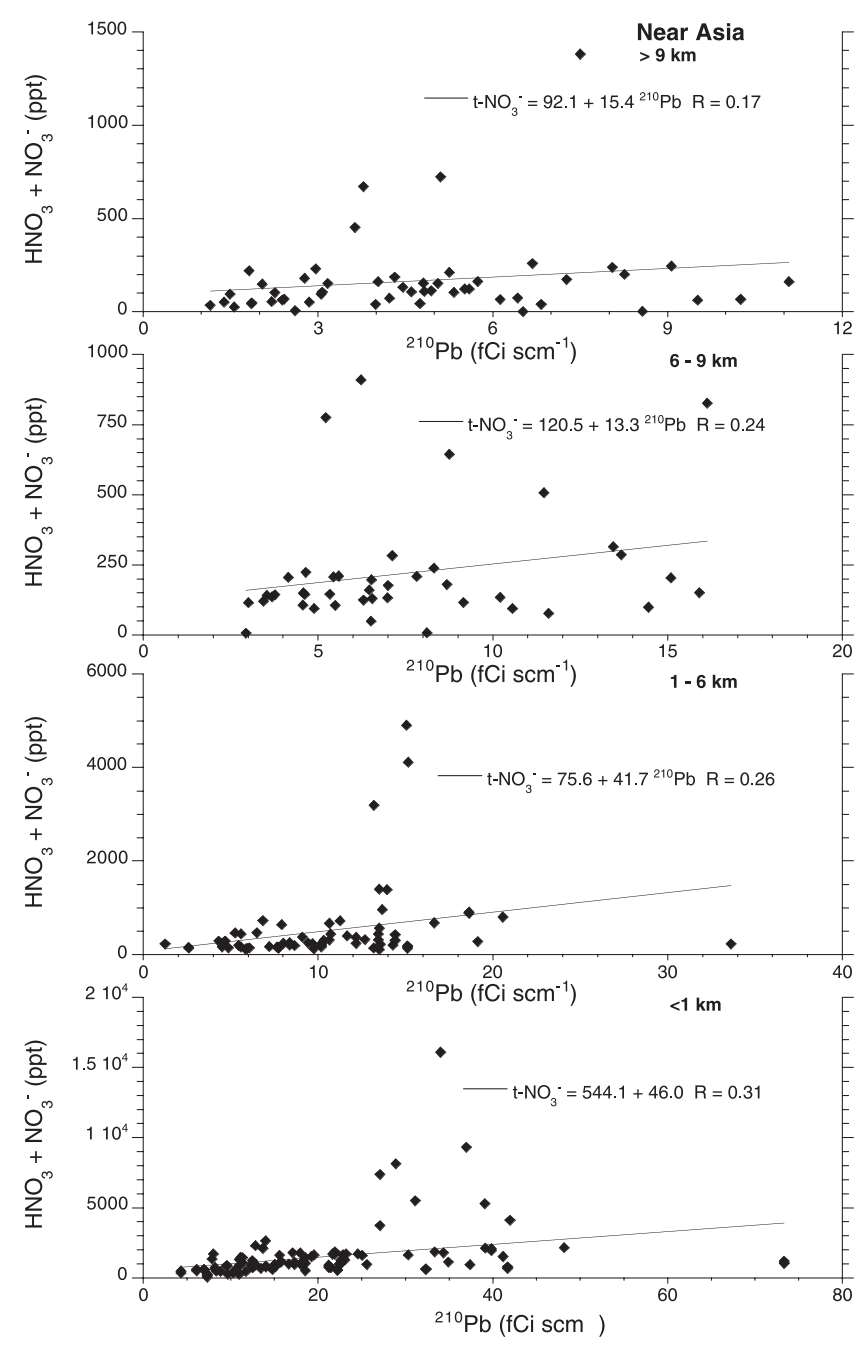

Figure 12. As in Figure 11 but for $\left(\mathrm{NO}_{3}^{-}+\mathrm{HNO}_{3}\right)$ against ${ }^{210} \mathrm{~Pb}$.

ences in synoptic scale meteorology or precipitation that would be likely to cause more dust outbreaks have been found between the PEM West B and TRACE-P study periods. We also examined the satellite precipitation products for several months before the DC-8 deployments in 1994 and 2001 and found no regions that were unusually arid which could have provided unusually strong dust emissions. Thus it appears that increased dust emissions from China reflect, in part, changing land use and anthropogenic activities [Menon et al., 2002]. Regardless of the detailed source(s) of the dust, evidence suggests that the increase in $\mathrm{Ca}^{2+}$ observed in TRACE-P could reflect greater dust export from Asia.

[30] On the other hand, Streets et al. [2003] estimate that Asian emissions of $\mathrm{SO}_{2}$ decreased by $17 \%$, while $\mathrm{NO}_{x}$ and $\mathrm{NH}_{3}$ emissions increased by 12 and $16 \%$, respectively, between PEM West B and TRACE-P. The increased emissions of $\mathrm{NO}_{x}$ and $\mathrm{NH}_{3}$ are about an order of magnitude lower than the changes we observed in $\mathrm{NO}_{3}^{-}$and $\mathrm{NH}_{4}^{+}$ (Figure 8), while decreasing $\mathrm{SO}_{2}$ emissions oppose significantly higher $\mathrm{SO}_{4}^{=}$. Having largely ruled out changes in the strength of both sources and sinks of pollution-derived aerosols requires that we reexamine the validity of the comparisons we have presented.

\subsubsection{Are the TRACE-P and PEM West B Data Sets Truly Comparable?}

[31] We readily grant that the remote Pacific bins defined in this paper are far from those defined in our earlier work on the PEM West data sets and in different flow regimes. However, the near Asian regions overlap considerably. The most obvious difference between near-Asia sampling in PEM West B and TRACE-P are the approximately 100 filters collected near the Yellow Sea and Chinese coast, in a region we noted was not sampled at all in PEM West B. This region includes all of the boundary layer heavily dustimpacted samples that originated in the Channel region identified by Jordan et al. [2003a]. These authors point out that many Channel samples also had elevated levels of aerosol-associated and gas phase pollutants. The Shanghai plume discussed in many of the companion papers in this issue (with mission maximum values of many species) was also encountered in this area, as were all of the $\mathrm{CO}_{2}$ plumes identified by Vay et al. [2003]. One might expect that adding a very polluted region to the TRACE $P$ near-Asia bins could elevate mean mixing ratios and create artifact enhancements when compared to the PEM West B near Asia data set.

[32] Excluding all samples collected in the region bounded by $27-37$ N, 120-135 E (see Figure 1) causes the mean $\mathrm{Ca}^{2+}$ mixing ratio in the boundary layer to decrease nearly $70 \%$, with a reduction just less than $50 \%$ in the lower troposphere bin (Figure 13). However, threefold enhancements over PEM West B averages are still apparent in the low-altitude TRACE-P bins. Considering the association of $\mathrm{NO}_{3}^{-}$and dust near Asia, it is not surprising that average $\mathrm{NO}_{3}^{-}$mixing ratios also decrease significantly (48 and 43\% in the boundary layer and $1-6 \mathrm{~km}$ bins, respectively) when samples from the dustiest part of the TRACE P study area are excluded. Here too, we note that the filtered TRACE-P low-altitude bins still exceed those in PEM West B by at least a factor of two. In contrast to the marked decreases in $\mathrm{Ca}^{2+}$ and $\mathrm{NO}_{3}^{-}$, average mixing ratios of $\mathrm{NH}_{4}^{+}$are reduced by no more than $28 \%$ and those of $\mathrm{SO}_{4}^{=}$by no more than $20 \%$ in all modified TRACE-P bins below $9 \mathrm{~km}$. As a result, TRACE-P still shows greater than twofold enhancements of $\mathrm{SO}_{4}^{=}$through much of the troposphere, with boundary layer $\mathrm{NH}_{4}^{+}$similarly enhanced (Figure 13).

[33] Even after removing an obvious sampling bias, we find that aerosol-associated tracers of pollution show large enhancements near Asia during TRACE-P that can not readily be attributed to increased source strength, or decreased sinks, when compared with PEM West B. Dust also increased between the two missions, though this may reflect previously documented increases in emissions from China. It seems that the enhancements of $\mathrm{NO}_{3}^{-}$and particularly $\mathrm{SO}_{4}^{=}$and $\mathrm{NH}_{4}^{+}$can only be explained as a consequence of sampling just a tiny fraction of a huge volume of atmosphere, when making in situ measurements from an airborne platform. TRACE-P demonstrated that the troposphere over the western Pacific is highly structured, such that very small changes in flight tracks could yield significantly different impressions of the composition of the region. A major focus of TRACE-P was to characterize continental 

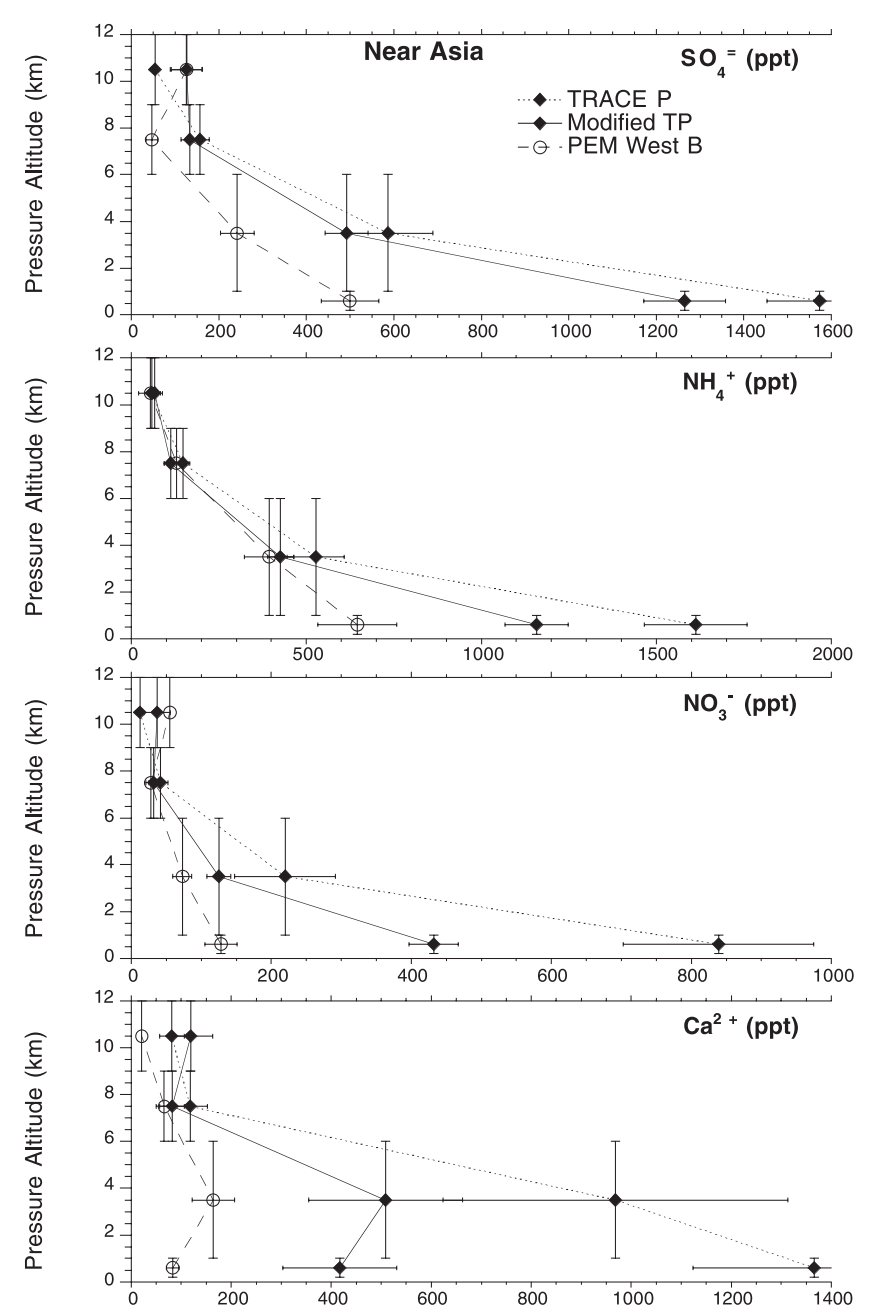

Figure 13. Comparison of the mean mixing ratios of $\mathrm{SO}_{4}^{=}$, $\mathrm{NH}_{4}^{+}, \mathrm{NO}_{3}^{-}$, and $\mathrm{Ca}^{2+}$ in four near-Asia altitude bins. A modified TRACE-P data set, excluding about 100 samples collected over the Yellow Sea, is compared to the full TRACE-P data set and PEM West B data shown in Figure 8.

outflow, while PEM West B was an exploratory mission with multiple objectives. Our otherwise unexplained enhancements in aerosol-associated species suggest that TRACE-P flight paths succeeded in sampling continental outflow more extensively than was the case in PEM West B.

[34] We also find that different binning of the same data set can impact the impression one is left with. A perfect example is seen in $\mathrm{HNO}_{3}$; in this paper we find very small increases near Asia between PEM West B and TRACE-P, yet Talbot et al. [2003] compare the heavily impacted Channel and Coastal air mass classes to fresh continental North air masses sampled in PEM West B and find TRACE-P to be fivefold higher. Similarly, Blake et al. [2003] find no systematic differences in a suite of NMHC binned to 2.5 degree patches, while Bartlett et al. [2003] find significant decreases in several of the same species when binned into different geographic regions. It may be that artifacts created by binning contribute to the contrast between the aerosol-associated pollutants (which are significantly higher in the TRACE-P data set) and the range of gaseous pollutants (which tend to show small differences compared to PEM West B). Perhaps the extreme heterogeneity of particle distributions in the atmosphere helps to make the observed distribution of aerosol-associated species more sensitive to small differences in sampling and data binning than is the case for trace gases.

\section{Conclusions}

[35] We have shown that the mixing ratios of soluble ions derived from soil dust and anthropogenic emissions were substantially higher in the near-Asia regions sampled by the DC-8 during TRACE-P compared with PEM West B. The enhancements in $\mathrm{Ca}^{2+}, \mathrm{NO}_{3}^{-}, \mathrm{SO}_{4}^{-}$, and $\mathrm{NH}_{4}^{+}$sharply contrast the distributions of many trace gases that are also derived from anthropogenic activities, yet were quite similar between the two missions. Asian emissions of the precursor gases that yield the aerosol-associated pollution tracers were estimated to have changed by less than $17 \%$ between 1994 and 2001. Likewise, we could find no evidence to support a hypothesis that aerosols were higher in 2001 due to less efficient scavenging by precipitation.

[36] It must be stressed that the enhancements we found were strongly dependent on the exact locations that were probed by the DC- 8 on each flight. TRACE-P objectives lead to many more flights specifically targeting continental outflow than was the case in PEM West B. Thus while the sampling regions overlapped a broad geographic area, TRACE-P flights often included repeated transects through small areas that were predicted to have strong continental outflow. On the larger scale, nearly $1 / 3$ of the filter samples we collected near Asia during TRACE-P were above the Yellow Sea and other coastal Chinese waters and hence frequently influenced by outflow events. No sampling was conducted in this region during PEM West B. When these near China samples are filtered out of the TRACE-P data set, enhancements of the ions associated with dust $\left(\mathrm{Ca}^{2+}\right.$ and $\mathrm{NO}_{3}^{-}$) decrease, from factors as high as 16 , to about 2-3 times higher than PEM West $\mathrm{B}$. Mean mixing ratios of $\mathrm{NH}_{4}^{+}$ and $\mathrm{SO}_{4}^{=}$also decrease when the TRACE-P data set does not include sampling very near China but by less than $28 \%$.

[37] Our observations do not necessarily imply that the troposphere over the western Pacific was more influenced by Asian emissions in 2001 than 1994. Rather, we feel that the enhancements we found largely confirm that TRACE-P DC-8 flights succeeded in sampling continental outflow more often than did those in PEM West B. However, it is not clear why more focused sampling in the regions of strong outflow did not also result in enhancements of trace gases emitted in Asia. We speculate that this may be further evidence of the extreme heterogeneity in the distribution of aerosols in the troposphere, especially close to major sources.

[38] Acknowledgments. As always, the flight and ground crews for the DC-8 provided outstanding service during TRACE-P. Support provided by "locals" in Kona, Guam, Hong Kong, Okinawa, and Yakota is also deeply appreciated. We also thank the many officials at various levels (that we rarely ever even met) throughout the Pacific that permitted and assisted DC-8 flights in and near their airspace. This research was supported by NASA's Global Tropospheric Chemistry Program.

\section{References}

Bartlett, K. B., G. W. Sachse, T. Slate, C. Harward, D. R. Blake, and N. J. Blake, Large-scale distribution of $\mathrm{CH}_{4}$ in the western Pacific: Sources 
and transport from the Asian continent, J. Geophys. Res., 108(D20), 8807, doi:10.1029/2002JD003076, in press, 2003.

Blake, N. J., D. R. Blake, I. Simpson, S. Meinarde, G. Sachse, M. Avery, S. Vay, and H. Fuelberg, NMHC and halocarbons in Asian continental outflow during TRACE P, J. Geophys. Res., 108(D20), 8806, doi:10.1029/2002JD003367, in press, 2003.

Carmichael, G. R., et al., Regional-scale chemical transport modeling in support of intensive field experiments: Overview and analysis of the TRACE-P observations, J. Geophys. Res., 108(D21), 8823, doi:10.1029/2002JD003117, in press, 2003.

Clarke, A. D., and V. N. Kapustin, A Pacific aerosol survey, part 1: A decade of data on particle formation, transport, evolution, and mixing in the troposphere, J. Atmos. Sci., 59, 363-382, 2002.

Dibb, J. E., R. W. Talbot, K. I. Klemm, G. L. Gregory, H. B. Singh, J. D. Bradshaw, and S. T. Sandholm, Asian influence over the western north Pacific during the fall season: Inferences from lead 210, soluble ionic species, and ozone, J. Geophys. Res., 101, 1779-1792, 1996.

Dibb, J. E., R. W. Talbot, B. L. Lefer, E. Scheuer, G. L. Gregory, E. V. Browell, J. D. Bradshaw, S. T. Sandholm, and H. B. Singh, Distributions of beryllium 7 and lead 210, and soluble aerosol-associated ionic species over the western Pacific: PEM West B, February-March 1994, J. Geophys. Res., 102, 28,287-28,302, 1997.

Dibb, J. E., R. W. Talbot, E. M. Scheuer, D. R. Blake, N. J. Blake, G. L. Gregory, G. W. Sachse, and D. C. Thornton, Aerosol chemical composition and distribution during the Pacific Exploratory Mission (PEM) Tropics, J. Geophys. Res., 104, 5785-5800, 1999a.

Dibb, J. E., R. W. Talbot, L. D. Meeker, E. M. Scheuer, N. J. Blake, D. R. Blake, G. L. Gregory, and G. W. Sachse, Constraints on the age and dilution of Pacific Exploratory Mission-Tropics biomass burning plumes from the natural radionuclide tracer ${ }^{210} \mathrm{~Pb}, J$. Geophys. Res., 104 , $16,233-16,241,1999 b$

Dibb, J. E., R. W. Talbot, G. Seid, C. Jordan, E. Scheuer, E. Atlas, N. J. Blake, and D. R. Blake, Airborne sampling of aerosol particles: Comparison between surface sampling at Christmas Island and P-3 sampling during PEM Tropics B, J. Geophys. Res., 107, 8230, doi:10.1029/ 2001JD000408, 2002. [printed 108(D2), 2003]

Eisele, F. L., et al., Informal instrument intercomparison summary, J. Geophys. Res., 108(D20), 8791, doi:10.1029/2002JD003167, in press, 2003

Fuelberg, H. E., C. M. Kiley, J. R. Hannan, D. J. Westberg, M. A. Avery, and R. E. Newell, Atmospheric transport during the Transport and Chemical Evolution over the Pacific (TRACE-P) experiment, J. Geophys. Res., 108(D20), 8782, doi:10.1029/2002JD003092, in press, 2003.

Gorzelska, K., R. W. Talbot, K. Klemm, B. Lefer, O. Klemm, G. L. Gregory, B. Anderson, and L. A. Barrie, Chemical composition of the atmospheric aerosol in the troposphere over the Hudson Bay lowlands and QuebecLabrador regions of Canada, J. Geophys. Res., 99, 1763-1779, 1994.

Gregory, G. L., J. T. Merrill, M. C. Shipham, D. R. Blake, G. W. Sachse, and H. B. Singh, Chemical characteristics of tropospheric air over the Pacific ocean as measured during PEM-West B: Relationship to Asian outflow and trajectory history, J. Geophys. Res., 102, 28,275-28,285, 1997.

Houghton, J. T., et al. (Eds.), Climate Change 2001: The Scientific Basis, Cambridge Univ. Press, New York, 2001

Husar, R. B., et al., Asian dust events of 1998, J. Geophys. Res., 106, $18,317-18,330,2001$.

Jacob, D. J., J. H. Crawford, M. M. Kleb, V. S. Connors, R. J. Bendura, J. L. Raper, G. W. Sachse, J. Gille, L. Emmons, and J. C. Heald, The Transport and Chemical Evolution over the Pacific (TRACE-P) mission Design, execution, and first results, J. Geophys. Res., 108(D20), 8781, doi:10.1029/2002JD003276, in press, 2003.

Jaffe, D., T. Anderson, D. Covert, R. Kotchenruther, B. Trost, J. Danielson, W. Simpson, T. Berntsen, S. Karlsdottir, D. Blake, J. Harris, G. Carmichael, and I. Uno, Transport of Asian air pollution to North America, Geophys. Res. Lett., 26, 711-714, 1999.

Jaffe, D., I. McKendry, T. Anderson, and H. Price, Six "new" episodes of trans-Pacific transport of air pollutants, Atmos. Environ., 37, 391-404, 2003

Jordan, C. E., J. E. Dibb, B. E. Anderson, and H. Fuelberg, Uptake of nitrate and sulfate on dust aerosols during TRACE-P, J. Geophys. Res., 108(D21), 8817, doi:10.1029/2002JD3101, in press, 2003a.

Jordan, C. E., et al., Chemical and physical properties of bulk aerosols within four sectors observed during TRACE-P, J. Geophys. Res. 108(D21), 8813, doi:10.1029/2002JD003337, in press, 2003b.
Lefer, B. L., et al., Enhancement of acidic gases in biomass burning impacted air masses over Canada, J. Geophys. Res., 99, 1721-1737, 1994. Liu, H., D. J. Jacob, I. Bey, R. M. Yantosca, B. N. Duncan, and G. W. Sachse, Transport pathways for Asian combustion outflow over the Pacific: Interannual and seasonal variations, J. Geophys. Res., 108(D20), 8786, doi:10.1029/2002JD003102, in press, 2003.

Ma, Y., et al., The characteristics and influence of biomass burning aerosols on fine particle ionic composition measured in Asian outflow during TRACE-P, J. Geophys. Res., 108(D21), 8816, doi:10.1029/ 2002JD003128, in press, 2003

Martin, B. D., H. E. Fuelberg, N. J. Blake, J. H. Crawford, J. A. Logan, D. R. Blake, and G. W. Saschse, Long-range transport of Asian outflow to the Equatorial Pacific, J. Geophys. Res., 108(D2), 8233, doi:10.1029/ 2001JD001418, 2003

McKendry, I. G., J. P. Hacker, R. Stull, S. Sakiyama, D. Mignacca, and K. Reid, Long-range transport of Asian dust to the lower Fraser Valley, British Columbia, Canada, J. Geophys. Res., 106, 18,361-18,370, 2001.

Menon, S., J. Hansen, L. Nazarenko, and Y. Luo, Climate effects of black carbon aerosols in China and India, Science, 297, 2250-2253, 2002.

Newell, R. E., and M. J. Evans, Seasonal changes in pollutant transport to the north Pacific: The relative importance of Asian and European sources, Geophys. Res. Lett., 27, 2509-2512, 2000.

Renner, R., A river of pollution, Env. Sci Technol., 34, 330A-331A, 2000.

Russo, R., et al., Chemical composition of Asian outflow over the western Pacific: Results from TRACE P, J. Geophys. Res., 108(D20), 8804, doi:10.1029/2002JD003184, in press, 2003.

Song, C. H., and G. R. Carmichael, Gas-particle partitioning of nitric acid modulated by alkaline aerosol, J. Atmos. Chem., 40, 1-22, 2001.

Staudt, A. C., D. J. Jacob, J. A. Logan, D. Bachiochi, T. N. Krishnamurti, and G. W. Sachse, Continental sources, transoceanic transport, and interhemispheric exchange of carbon monoxide over the Pacific, J. Geophys. Res., 106, 32,571-32,589, 2001.

Streets, D. G., et al., An inventory of gaseous and primary aerosol emissions in Asia in the year 2000, J. Geophys. Res., 108(D21), 8809, doi:10.1029/2002JD003093, in press, 2003.

Talbot, R., et al., Reactive nitrogen in Asian continental outflow over the western Pacific: Results from the NASA TRACE-P airborne mission, J. Geophys. Res., 108(D20), 8803, doi:10.1029/2002JD003129, in press, 2003.

Thulasiraman, S., N. T. O’Neill, A. Royer, B. N. Holben, D. L. Westphal, and L. J. B. McArthur, Sunphotometric observations of the 2001 Asian dust storm over Canada and the U. S., Geophys. Res. Lett., 29(8), 1255, doi:10.1029/2001GL014188, 2002.

Tratt, D. M., R. J. Frouin, and D. L. Westphal, April 1998 Asian dust event: A southern California perspective, J. Geophys. Res., 106, 18,371$18,379,2001$

Uno, I., H. Amano, S. Emori, K. Kinoshita, I. Matsui, and N. Sugimoto, Trans-Pacific yellow sand transport observed in April 1998: A numerical simulation, J. Geophys. Res., 106, 18,331-18,344, 2001.

Vaughan, J. K., C. Claiborn, and D. Finn, April 1998 Asian dust event over the Columbia Plateau, J. Geophys. Res., 106, 18,381-18,402, 2001

Vay, S., et al., The influence of regional-scale anthropogenic activity on CO2 distributions over the western Pacific, J. Geophys. Res., 108(D20), 8801, doi:10.1029/2002JD003094, in press, 2003.

Wilkening, K. E., L. A. Barrie, and M. Engle, Trans-Pacific air pollution, Science, 290, 65-67, 2000 .

Xiao, H., G. R. Carmichael, J. Durchenwald, D. Thornton, and A. Bandy, Long-range transport of $\mathrm{SO}_{x}$ and dust in east Asia during the PEM B experiment, J. Geophys. Res., 102, 28,589-28,612, 1997.

M. A. Avery, NASA Langley Research Center, Hampton, VA 23665, USA. (m.a.avery@larc.nasa.gov)

J. E. Dibb, R. W. Talbot, E. M. Scheuer, and G. Seid, Climate Change Research Center, Institute for the Study of Earth, Oceans, and Space, Morse Hall, University of New Hampshire, Durham, NH 03825, USA. (jack. dibb@unh.edu)

H. B. Singh, NASA Ames Research Center, Moffett Field, CA 94035, USA. 